Shiva, A., Sobouti, F., Priestley, K., Ghods, A., Motaghi, K., Tilmann, F., Eken, T. (2021): Seismic anisotropy and mantle deformation in NW Iran inferred from splitting measurements of SK(K)S and direct $\mathrm{S}$ phases. - Geophysical Journal International, 226, 2, 1417-1431.

https://doi.org/10.1093/gji/ggab181 


\title{
Seismic anisotropy and mantle deformation in NW Iran inferred from splitting measurements of $\mathrm{SK}(\mathrm{K}) \mathrm{S}$ and direct $\mathrm{S}$ phases
}

\author{
Shiva Arvin, ${ }^{1}$ Farhad Sobouti, ${ }^{1}$ Keith Priestley, ${ }^{2}$ Abdolreza Ghods, ${ }^{1}$ Khalil Motaghi, ${ }^{1}$ \\ Frederik Tilmann ${ }^{\circledR 3,4}$ and Tuna Eken ${ }^{5}$ \\ ${ }^{1}$ Department of Earth Sciences, Institute for Advanced Studies in Basic Sciences (IASBS), Zanjan 45137-66731, Iran. E-mail: shivarvn@gmail.com \\ ${ }^{2}$ Department of Earth Sciences, Bullard Laboratories, University of Cambridge, Cambridge CB3 OEZ, UK \\ ${ }^{3}$ Department of Geophysics, Deutsches GeoForschungsZentrum GFZ, 14473 Potsdam, Germany \\ ${ }^{4}$ Department of Earth Sciences, Institute of Geological Sciences, Freie Universität, Berlin 14195, Germany \\ ${ }^{5}$ Department of Geophysical Engineering, Faculty of Mines, Istanbul Technical University, 34469, Maslak/Istanbul, Turkey
}

Accepted 2021 May 4. Received 2021 April 27; in original form 2020 December 30

\begin{abstract}
SUMMAR Y
We present the results of a shear wave splitting analysis performed on the teleseismic SK(K)S and direct $S$ wave recordings of 68 temporary broad-band stations to investigate the mantle deformation on the northern side of the Arabia-Eurasia collision zone in NW Iran. We used the Reference Station Technique to overcome potential contamination from the source-side anisotropy on the direct $S$ wave signals. This method enabled us to expand our splitting measurement database beyond the usual SK(K)S phases. The average splitting delay time over the entire region was found to be $1.14 \pm 0.42 \mathrm{~s}$ for the $\mathrm{SK}(\mathrm{K}) \mathrm{S}$ wave and $1.36 \pm 0.26 \mathrm{~s}$ for the direct $S$ wave. In most parts of the study area, the fast polarization directions for both shear phases are consistent and show a uniform NE-SW direction with an average of $36^{\circ}$ and $37^{\circ}$ for $\mathrm{SK}(\mathrm{K}) \mathrm{S}$ and $S$ wave-derived results, respectively. This direction is in close agreement with the direction of the absolute plate motion vector in NW Iran $\left(\mathrm{N} 39^{\circ} \mathrm{E}\right)$. The fast directions are associated with neither the surface geological trends, nor the geodetic strain fields. We propose that the observed anisotropy is mainly controlled by the LPO fabric developed due to the shearing of the asthenospheric layer in response to the motion of the lithosphere relative to the deeper mantle. Only in a narrow region near the tectonic boundaries of central Iran with NW Iran and the Alborz, NW-SE oriented SK(K)S fast directions tend to align with the major geological structures. Fast directions obtained from direct $S$ wave indicate significantly smoother variations in the same regions and mostly continue to be aligned in the NE-SW direction. We attribute these differences to the change in the structure of the lithosphere in the tectonic boundary zone. The western margins of central Iran possess a strong deformational fabric as evidenced by the major active strike-slip zones there. Considering that the depth extent of this fabric expands over a relatively narrow zone in the mantle, it can locally influence the $\mathrm{SK}(\mathrm{K}) \mathrm{S}$ phases. The direct $S$ waves, on the other hand, have a larger footprint and therefore average over a larger region, and relative to the $\mathrm{SK}(\mathrm{K}) \mathrm{S}$ phases, are influenced more strongly by the asthenospheric fabric due to their larger angles of incidence, which results in a larger zone of influence for station average anisotropy parameters.
\end{abstract}

Key words: Seismic anisotropy; Continental tectonics: compressional; Dynamics of lithosphere and mantle.

\section{INTRODUCTION}

The present-day tectonics of Iran has resulted from the continental collision of the Arabian and Eurasian plates. Ever since the closure of the Neo-Tethys Ocean in the late Oligocene (25 Ma) in Iran (Mouthereau et al. 2012), the progressive underthrusting of the Arabian passive margin beneath central Iran (Paul et al. 2006;
Motaghi et al. 2017) has resulted in the formation of a broad orogenic plateau, bounded by the thrust-and-fold belt of the Zagros in the south, and the Alborz and Kopet Dag in the north (Agard et al. 2011). Collision has resulted in the formation of a very thick lithospheric root of up to $230-250 \mathrm{~km}$ in the Zagros that is in sharp contrast with the thinner lithosphere of the rest of Iran (Priestley et al. 2012; Motaghi et al. 2015; Tunini et al. 2015, 2017). 
There have been extensive discussions about the fate of the subducted oceanic lithosphere, and whether or not it is still attached to the Arabian lithosphere with numerous investigations offering various geophysical and geological evidence for a post-collisional slab break-off under the Zagros orogeny (e.g. Agard et al. 2011; Mouthereau et al. 2012; van der Meer et al. 2018; Mahmoodabadi et al. 2019). On the other side of the collision zone, in central Iran and regions to its north, observations of seismically low-velocity shallow mantle (e.g. Al-Lazki et al. 2004; Kaviani et al. 2007; Rastgoo et al. 2018; Mahmoodabadi et al. 2019; Rahmani et al. 2019) and post-collisional magmatic activities (Omrani et al. 2008; Chiü et al. 2013) have prompted several authors to suggest that warm upward asthenospheric flow fields have influenced the evolution of the lithospheric structure after the start of collision (e.g. Amini et al. 2012; Mahmoodabadi et al. 2020). The deformation of the lithosphere in the collision zone therefore, is probably closely intertwined with the upper mantle flow field beneath. An important aspect of the study of the dynamics of the collision zone is to understand the relationship between the mantle flow field and the surface deformation inferred from tectonics. One other subject is whether or not the lithosphere deforms coherently. This is an important issue, since it can shed light on how shortening is accommodated and how faulting near the surface is continued into the lower part of the lithosphere.

Lithospheric and mantle deformation can be efficiently constrained by measurements and models of seismic anisotropy. Specifically, shear wave splitting parameters derived from waves travelling in an anisotropic mantle can give hints about the presentday patterns of mantle flow, as well as the present and past deformation history of the lithospheric mantle (Silver 1996). The mapping of splitting patterns is therefore crucial for our understanding of the dynamics of continental deformation throughout different tectonic domains and across boundaries separating those domains.

For the quantification of seismic anisotropy in the mantle, polarization analyses of split shear waves are often used as a direct diagnostic tool. Shear waves entering an anisotropic medium are split into fast and slow components. Among various types of shear waves, core-mantle refracted shear waves, $\mathrm{SK}(\mathrm{K}) \mathrm{S}$, are the most popular phases to determine the mantle anisotropy because their polarity prior to entering the anisotropic medium below the receiver can be assumed to be radial $(R)$. Therefore, the presence of energy on the transverse component $(T)$ giving rise to elliptical particle motion is the main diagnostic feature of anisotropic structure (Savage 1999). The two splitting parameters are the time delay between the fast and slow wave $(\delta t)$, which depends on both the strength of anisotropy and the thickness of the anisotropic layer, and the fast polarization direction (FPD), which indicates the orientation of the fast axis of anisotropy (Silver \& Chan 1991).

The lattice preferred orientation of anisotropic olivine crystals in the upper $400 \mathrm{~km}$ of the mantle is considered to be the major source for shear-wave anisotropy as measured by teleseismic shear wave splitting (Karato et al. 1995). The FPDs tend to orient parallel to the fast $a$-axis of olivine crystals and are often used as a proxy for the direction of mantle strain or flow (Silver \& Chan 1991; Savage 1999). The steep-angle arrival of split SK(K)S waves at the receiver provides excellent lateral resolution for splitting measurements in the upper mantle, and enables a direct comparison of anisotropy with surface tectonic and geologic features possessing typical continental dimensions.
Although splitting measurements obtained from SK(K)S phases are a well-established tool to map seismic anisotropy, analysis of complex anisotropy is often limited by poor azimuthal coverage. In contrast, direct teleseismic $S$ waves tend to be more frequently recorded with good signal-to-noise ratios due to the larger distance range, over which they are observed, and also due to the smaller distances. They show a larger variety of incidence angles and polarization directions. Direct $S$ waves have been used to estimate sourceside region anisotropy of the subslab environment after correcting $S$ wave signals for previously known receiver-side anisotropy. Lynner et al. (2017) reported that source-side splitting measurements for the events at short distances and thus with large incidence angles can be influenced by different types of LPO fabrics developed under local stress, temperature and water content conditions within subduction environments. The problem can also arise when the main goal is to image variation of anisotropic parameters beneath the receiver-side since these waves can be easily contaminated by undesired sourceside anisotropy. To overcome this issue, deep-focus earthquakes in subduction zones have been suggested as suitable sources of $S$ waves uncontaminated by source side anisotropy, as the mantle below 300-400 km depth is generally thought to be largely isotropic (e.g. Savage et al. 1990; Long \& van der Hilst 2005). However, Wookey et al. (2002) observed that deep events were actually affected by slab and subslab anisotropy; presumably due to the lower temperatures in subducting slabs, anisotropic fabrics can persist to larger depths. Furthermore, for temporary deployments, usually only a small number of deep-focus events are recorded. Therefore, we used the Reference Station Technique (RST) developed by Eken \& Tilmann (2014) to remove the potential contamination of the direct $S$ phases by source-side anisotropy in shear wave splitting analysis. As an array-based approach, the RST makes use of waveform comparisons at two closely spaced stations (reference and target stations) for which source-side anisotropy can be regarded as identical. The optimum splitting parameters beneath a target station, can then be estimated through a grid search procedure where the target station is corrected for tentative splitting parameters. If splitting is present at the reference station, it is corrected for receiver-side anisotropy prior to the analysis. The maximum similarity of the corrected $S$ wave signal beneath the reference station and target station represents the best estimate of splitting parameters for the respective station pair and event; final splitting parameters are derived by averaging the results from many events and station-pairs. The RST has been applied to the regions with various tectonic settings, such as in the Tibetan Plateau (Eken \& Tilmann 2014; Singh et al. 2016; Tiwari et al. 2017) and the Hellenic Trench in the eastern Mediterranean (Confal et al. 2016).

In this work, we focus on the northwestern corner of the Iranian plateau, covering the western Alborz and Talesh Mountains, NW Iran and parts of the northern margin of central Iran (Fig. 1). By using $\mathrm{SK}(\mathrm{K}) \mathrm{S}$ and direct $S$ wave splitting analyses, we will investigate the anisotropic nature of the mantle in a part of the Arabia-Eurasia collision zone where several of the constituent tectonic blocks of Iran come into contact. Our aim is to identify the dominant source of anisotropy in order to infer the pattern of mantle deformation as it responds to the forces of continental convergence. We used the recordings of three temporary seismic arrays deployed in the region at different time periods between 2008 and 2016. Including both $\mathrm{SK}(\mathrm{K}) \mathrm{S}$ and direct $S$ waves in the splitting measurements notably improved the range of initial polarization angles (equivalent to backazimuths for SK(K)S events) and azimuthal coverage. 


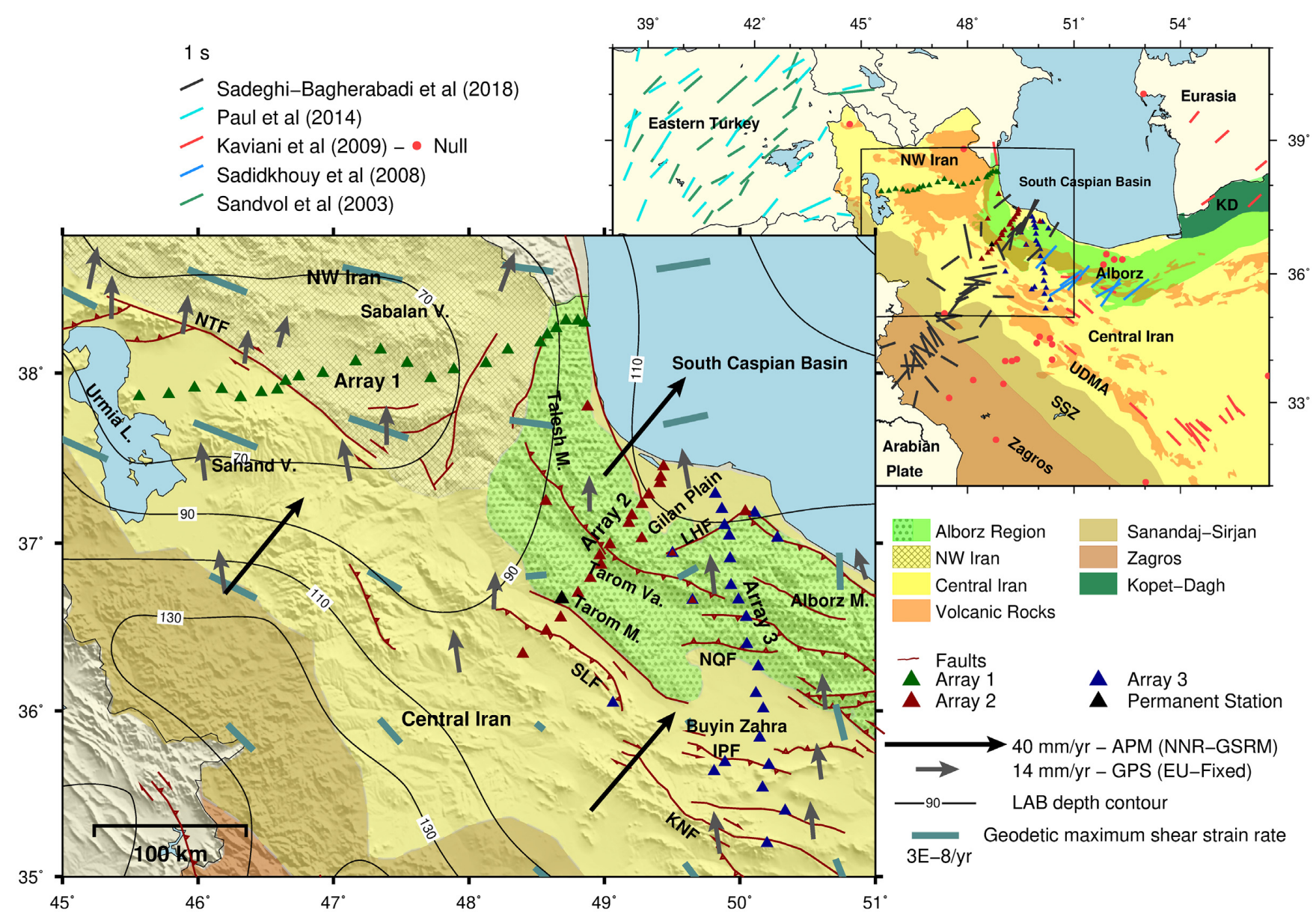

Figure 1. The regional tectonic and topographic map showing the seismic arrays used in the present study. The red lines show the trace of the active faults, taken mostly from Hessami et al. (2003). The temporary IASBS/CAM seismic arrays are shown by colored triangles. Station names are mentioned in the subsequent figures. The SK(K)S fast directions obtained from previous studies are also shown. Contour lines show variations of lithospheric thickness adopted from Mortezanejad et al. (2019). The black and grey arrows are the plate motion vectors from Kreemer et al. (2014) and GPS vectors (relative to stable Eurasia) from Khorrami et al. (2019), respectively. The dark slate grey bars are the strike of the geodetic maximum shear strain rate in Iran (Raeesi et al. 2017). Fault and region abbreviations: LHF, Lahijan Fault; NTF, North Tabriz Fault; NQF, North Qazvin Fault; SLF, Soltanieh Fault; KNF, Kushk-e Nosrat Fault; IPF, Ipak Fault; KD, Kopet-Dagh; UDMA, Urumieh-Dokhtar Magmatic Arc; SSZ, Sanandaj-Sirjan Zone.

\section{REGIONAL TECTONIC SETTING AND PREVIOUS ANISOTROPY STUDIES}

The Arabia-Eurasia collision has resulted in the formation of the central Iran Plateau. In western Iran the plateau is bounded on its foreland side by the Zagros Mountains, and on the hinterland by the Alborz and Talesh Mountains. The South Caspian Basin (SCB) on the northern end acts as a rigid backstop to the forces of continental shortening (e.g. Ghods et al. 2015). North of the Zagros suture lie the Sanandaj-Sirjan Zone (SSZ) and the Urumieh-Dokhtar Magmatic Arc (UDMA), which developed as the arc regions of the Neo-Tethyan subduction in the Mesozoic and Cenozoic, respectively (Agard et al. 2011). Central Iran as a distinct continental block separates the SSZ and UDMA from the Alborz. These disparate tectonic blocks were assembled in the last $25 \mathrm{Myr}$ as part of the ongoing continental collision process (e.g. Agard et al. 2011). Our study region covers the northern part of this geological setting from the UDMA to the southwestern margins of the SCB (Fig. 1). The constituent blocks are characterized by different present-day styles of deformation. In the mountain belts the deformation is mainly accommodated by folding and thrust faulting (e.g. Nissen et al. 2011), while in central Iran crustal thickening is largely absent and shortening (at a relatively slow rate) is accommodated on sets of major strike-slip fault zones (Allen et al. 2011). In our region of interest these strike-slip zones include the North Tabriz, Soltanieh and Kushk-e Nosrat faults. Seismic tomography and other seismological techniques have revealed a great deal of variation in lithospheric and upper mantle structure from south to north of the collision zone. In the Zagros and SSZ, high upper-mantle seismic velocities reveal a thick lithosphere of the Arabian margin underthrusting central Iran (e.g. Paul et al. 2010; Motaghi et al. 2017; Rahmani et al. 2019). Receiver function studies and ambient noise tomography further clearly imaged the Arabian mid-lower crust underthrusting the crust of central Iran along the Main Zagros thrust (e.g. Paul et al. 2006; Nissen et al. 2011; Pilia et al. 2020). Surface wave tomography images show that in the Zagros a high shear wave-speed lid extends to a depth of $225 \mathrm{~km}$ (Priestley et al. 2012; Motaghi et al. 2015). Similarly, under the SCB upper mantle velocities are high, indicating a large lithospheric thickness (Priestley et al. 2012). In contrast in central Iran, NW Iran and the Alborz, low uppermost mantle wave speeds point to the presence of a thinner lithosphere and warm mantle (Al-Lazki et al. 2004; Maggi \& Priestley. 2005; Amini et al. 2012; Rahmani et al. 2019). Two body wave 
tomographic models using joint regional and teleseismic phases (Bavali et al. 2016; Motaghi et al. 2018) in NW Iran have shown a sharp contrast between high-velocities in the upper mantle under the SCB and low-velocities in the neighbouring NW Iran and western Alborz regions. Mortezanejad et al. (2019) converted the Rayleigh wave group velocity dispersion data for shear wave velocity in NW Iran and derived a map of lithospheric thickness variations in our study area (Fig. 1). According to this map, the lithospheric thickness is as low as $70 \mathrm{~km}$ in NW Iran, increasing to more than $120 \mathrm{~km}$ towards NW Zagros in the south and SCB in the east. Quantitative analysis of $P$ and $S$ receiver functions (Taghizadeh-Farahmand et al. 2010) gave an estimate of $85 \mathrm{~km}$ for the thickness of the lithosphere in NW Iran. Another receiver function analysis (Mohammadi et al. 2013) imaged the lithosphere to decrease from a thickness of $\sim 200 \mathrm{~km}$ in west-central Zagros and SSZ to $80-90 \mathrm{~km}$ in central Iran and central and eastern Alborz. Late Cenozoic magmatism throughout much of central Iran and the Alborz also attest to a warm shallow upper mantle (Omrani et al. 2008; Chiü et al. 2013).

Previous seismic anisotropy studies in Iran and neighbouring regions have revealed much about the anisotropic structure of the Arabia-Eurasia collision zone. Kaviani et al. (2009) observed from $\mathrm{SK}(\mathrm{K}) \mathrm{S}$ splitting measurements that seismic anisotropy in Iran shows internal consistency in each individual tectonic block but varies sharply between them. They argued that the heterogeneous nature of the anisotropic field in Iran might be influenced by the deformation fabric of the lithosphere rather than the flow fabric of the asthenosphere. According to them the agreement between the observed directions of anisotropy with the direction of maximum shear as inferred from geodetic measurements implies a vertically coherent deformation within the lithosphere of Iran. SadeghiBagherabadi et al. 2018a, 2018b) examined the shear wave splitting of the $\mathrm{SK}(\mathrm{K}) \mathrm{S}$ phases along a seismic array in western Iran across the collision zone from the Zagros to the Alborz. Their work revealed that while in the Zagros, the thick lithospheric root accounts for the along-strike fast polarization directions, in central Iran and the Alborz, the asthenospheric mantle flow field in the far-field away from the collisional front is responsible for the observed fast directions, which trend subparallel to the absolute plate motion (APM) vectors. They contended that the complex and variable pattern of fast polarization directions (FPD) under central Iran could reflect a small-scale organization of the mantle flow field under a lithosphere with a significant thickness gradient. Also, Sadidkhouy et al. (2008) observed fast SKS directions in northern Iran that were subparallel to the APM vector, suggesting an asthenospheric origin for the observed anisotropy. Also, on the Anatolian side of the Turkish-Iranian plateau, SK(K)S studies (Sandvol et al. 2003; Paul et al. 2014; Confal et al. 2016, 2018) show a dominant NE-SW oriented FPDs, with almost no abrupt changes in directions across the main tectonic boundaries. Together with relatively thin lithospheric thickness estimates ( $~ 90-100 \mathrm{~km}$ ) from $S$ receiver functions across entire Anatolia (Kind et al. 2015), these splitting parameters were explained by a large-scale sublithospheric flow beneath the Anatolian plate as the primary origin of seismic anisotropy (Paul et al. 2014; Confal et al. 2018).

\section{DATA AND METHODS}

The broad-band seismic data used in this study were recorded by 68 seismic stations in three temporary arrays in NW Iran installed and operated non-concurrently between 2008 and 2016 by the Institute

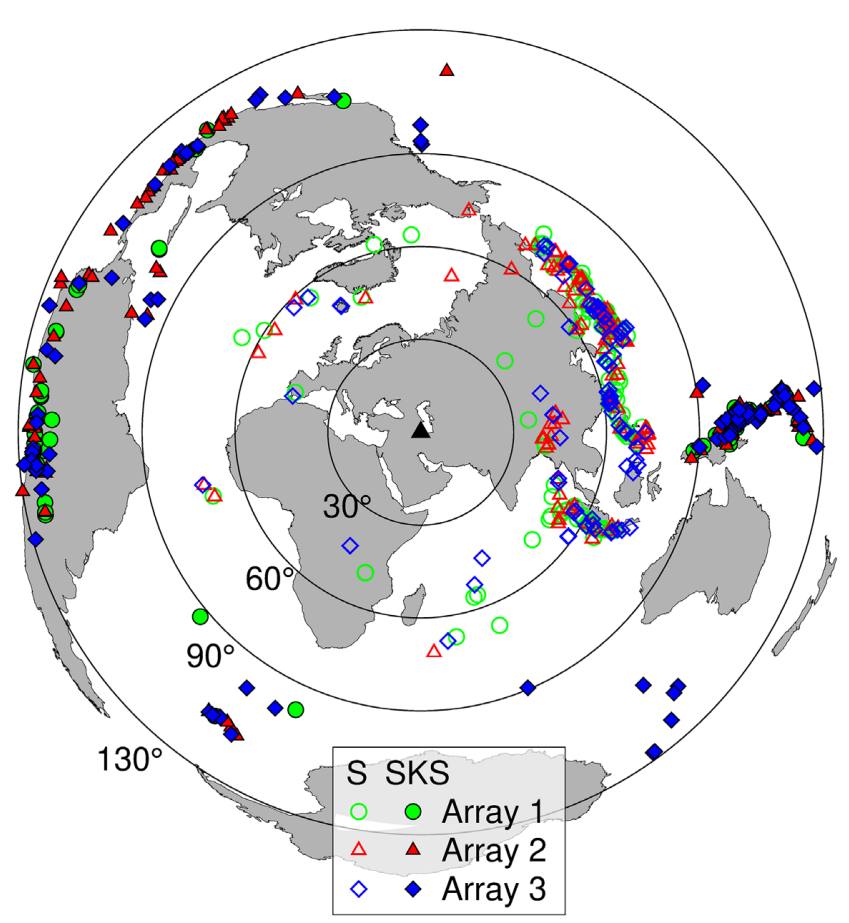

Figure 2. Azimuthal and distance distribution of the teleseismic events used in this study.

for Advanced Studies in Basic Sciences (IASBS) and University of Cambridge, and one permanent station of the Iranian National Seismic Network (INSN, Fig. 1). The temporary arrays were mainly linear profiles that traversed the Talesh and western Alborz Mountains, NW Iran and parts of the central Iran Plateau to the vicinity of the UDMA. The average inter-station distance on the profiles was about $13 \mathrm{~km}$. The stations were repositioned during deployment and the recording span at individual stations varied between 4 and 31 months.

We used two data sets in this study. For the SK(K)S splitting measurements we used teleseismic earthquakes with magnitudes greater than 5.5 and epicentral distances between $90^{\circ}$ and $130^{\circ}$, and for the direct $S$ wave analysis we considered events larger than magnitude 5.5 within a distance range from $40^{\circ}$ to $80^{\circ}$ (Fig. 2). The reason why we select direct $S$ wave signals of the events with distances greater than $40^{\circ}$ is to avoid possible complications, which may stem from phase shifts due to the surface reflection at shallow angles of incidence (Savage 1999). A total number of 2764 teleseismic events, mostly in the eastern hemisphere, met the above conditions. More information about the three arrays and the number of events analysed is given in Table S1.

\section{SK(K)S analysis}

We carried out the $\mathrm{SK}(\mathrm{K}) \mathrm{S}$ splitting analysis by applying the transverse-component minimization method (SC) of Silver \& Chan (1991) on individual records to measure the splitting parameters, the fast polarization direction, FPD and the delay time, $\delta t$. The method relies on finding the best-fitting splitting parameters in a grid search scheme by assuming a single-layer medium of transverse anisotropy with horizontal axis of symmetry.

We cross-checked with the rotation-correlation (RC) method of Bowman \& Ando (1987) and only retained measurements when 
both methods yielded consistent estimates for the splitting parameters. Similar to Wüstefeld \& Bokelmann (2007), we performed a comparison between results from these two methods and then we kept the measurements as good non-null results if $\mid \mathrm{FPD}_{\mathrm{RC}}-\mathrm{FPD}_{\mathrm{SC}}$ $\mid<8^{\circ}$ and $0.8<\delta t_{\mathrm{RC}} / \delta \mathrm{t}_{\mathrm{SC}}<1.1$, and as good null results if $37^{\circ}<$ $\left|\mathrm{FPD}_{\mathrm{RC}}-\mathrm{FPD}_{\mathrm{SC}}\right|<53^{\circ}$ and $\delta t_{\mathrm{RC}} / \delta t_{\mathrm{SC}}<0.2$. As SC is more robust in the presence of noise (Vecsey et al. 2008), we only retained those measurements for further processing. We used the SplitLab software developed by Wüstefeld et al. (2008) to carry out the analysis (see Fig. S1 for an example).

Before proceeding with data analysis we removed the instrument response from the waveforms and visually inspected them to ensure that the noise level was low and the $\mathrm{SK}(\mathrm{K}) \mathrm{S}$ waveform was recognizable and not distorted by the presence of other phases. Individual seismograms were band-pass filtered with variable cutoff frequencies in order to improve the signal-to-noise ratio $(\mathrm{S} / \mathrm{N})$ and waveform quality. The low and high cutoffs were varied from 0.03 to $0.05 \mathrm{~Hz}$, and 0.12 to $0.25 \mathrm{~Hz}$, respectively. The analysis window for $\mathrm{SK}(\mathrm{K}) \mathrm{S}$ was chosen manually to include at least one period of the signal around the theoretical arrival time (calculated from the IASP91 model). We varied the window position and length until we obtained measurements that showed little change with window variation. The final splitting parameters were chosen based on the following five quality criteria: (1) an $\mathrm{S} / \mathrm{N}$ ratio greater than 5 for the original radial component inside the analysis window, (2) $2 \sigma$ error less than $\pm 30^{\circ}$ for FPD, and $\pm 1.0 \mathrm{~s}$ for $\delta t$, (3) similarly shaped pulses for the estimated fast and slow components, (4) minimum energy on the corrected transverse component and (5) elliptical particle motion before correcting for anisotropy and linear or nearlylinear particle motion after correction. Criteria 3-5 are subjective and are based on visual inspection of the waveforms. Measurements with good $\mathrm{S} / \mathrm{N}$ ratio and initial linear particle motion were treated as null results. Null measurements indicate that the shear waves do not split. There are two reasons for this: either the upper mantle beneath the receiver is isotropic, or the incoming polarization of the phase has the same direction as the fast or slow axis of anisotropy. After implementing aforementioned selection criteria, we were left with 637 reliable non-null and 170 reliable null measurements from 287 teleseismic events for further analysis. The details of the statistics for each array are given in Table S1.

\section{Direct $S$ wave analysis}

The direct $S$ waves splitting analysis was performed through the Reference Station Technique (RST) developed by Eken \& Tilmann (2014). This technique utilizes two horizontal components at two closely located stations (referred as target and a reference station) less than $300 \mathrm{~km}$ apart. Eken \& Tilmann (2014) suggested that this distance threshold would be sufficient to assume that the potential influence of the region outside receiver side would be almost identical along the ray path in the source side region and the deeper part of mantle for both stations. The most important advantage of this method over conventional methods is that it eliminates the potential contamination effect of the source-side anisotropy on the measurements by minimizing the misfit function between the corrected seismic waveforms at the reference and target stations. The RST relies on the a priori knowledge of receiver-side seismic anisotropy at the reference stations, which could be obtained from various measurement/modeling tools [e.g. SK(K)S splitting measurements, azimuthal inversion of surface waves, etc.]. This approach initially involves a backward angular rotation and time-shift applied as an inverse splitting operator (based on known anisotropic parameters at the reference station) to the two horizontal components of the reference station. The result of this correction is assumed to recover the signal representing only source side anisotropy at the reference station, which then also can be assumed to characterize the waveform below the target station prior to entering the anisotropic layer. The next step is to carry out a grid search in which all possible splitting pairs are tested to correct receiver-side anisotropic parameters beneath the target station. Finally, those parameters yielding the maximum similarity between corrected signals of reference and target stations are assigned as optimum splitting parameters for the receiver-side of the target station.

The RST attributes all waveform differences between reference and target stations to the effect of anisotropic structure. In reality, isotropic velocity variations, for example differences in the thickness of the crust and near surface sediments may have a potential role on possible variations in waveforms. In our study region, the Caspian coastal region is underlain by a very thick (19-15 km), very-low velocity sedimentary sequence on top of a higher-thanaverage velocity crystalline basement, in great contrast with the adjacent mountain regions where the crust is substantially thicker and its sedimentary cover is thin (Mangino \& Priestley 1998). Such a situation could cause short-scale variations in the SK(K)S measurements. Eken \& Tilmann (2014), however, have demonstrated with synthetic models that the effect of potential variations in the thickness of crust and sedimentary layer between reference and target stations on expected splitting parameters would be small. For each pair of splitting parameters, the method also provides two auxiliary parameters: the isotropic time delay, $\Delta t$, which is indicative of the difference in traveltimes due to lateral heterogeneities, and the amplitude factor, $\alpha$, which is a measure of the amplitude ratio between the two stations and is a measure of differences in site response. $\alpha=0.5$ implies that no amplitude correction is required, $\alpha<0.5$ means the amplitude at the target station is less than that at the reference station while $\alpha>0.5$ indicates the reverse.

Whereas at least one reference station with independent constraints is needed to avoid circularity of the estimate, Eken \& Tilmann (2014) have demonstrated that an iterative bootstrapping approach could provide a reliable estimate of splitting measurements for seismic deployments, in which only a few stations with well-constrained SK(K)S splitting parameters are used as seeds.

In this approach, after calculating the splitting parameters using an initial set of reference stations, the results for these target stations with newly estimated splitting parameters are added to the list of reference stations with assumed known anisotropy. This process enables splitting estimates for the newly added reference stations to be simultaneously improved by continuing to treat them as target stations, too.

In practice, some of the stations with insufficient or low-quality data can be automatically excluded if no reliable splitting parameters can be estimated for them. In the first step of applying the RST method we identified all possible station pairs with referencetarget distances less than $300 \mathrm{~km}$ and for each array we chose three initial reference stations with reliable station-averaged splitting parameters inferred from good-quality individual SK(K)S splitting measurements.

We removed the instrument response from the waveforms and visually inspected them to discard low-quality and noisy signals. The analysis window was set between $15 \mathrm{~s}$ before and $30 \mathrm{~s}$ after the theoretical $S$ wave arrival to minimize possible contamination by converted phases and coda waves. We discarded events with an arrival time difference of less than $30 \mathrm{~s}$ between the direct $S$ and 
other phases such as SK(K)S and ScS. Finally, we applied a 0.03$0.2 \mathrm{~Hz}$ bandpass filter to all seismograms.

The uncertainties in the individual splitting parameters were estimated by the inverse F-test approach of Silver \& Chan (1991), which is a statistical measure of the errors and works via comparing the variation in the residual energy distribution above the minimum of the misfit surface with the variation based on a preset confidence level of 95 per cent.

The causes for null measurements for the direct- $S$ waves are similar to those for the SK(K)S phases as explained earlier. To prevent a null measurement to be included in the non-null results, the RST performs a null-split reject test, where the $F$-test again compares the residual energy at the actual minimum with the calculated residual energy under the assumption of null splitting to determine how strongly the data exclude null splitting in a statistical sense.

We applied a stepwise quality assessment to achieve consistency of the results and retained only measurements that: (1) had a normalized residual energy smaller than 0.5 to ensure that the assumption of identical source-side splitting and absence of strong scattering phases is roughly satisfied, (2) had an $\alpha$ value between 0.4 and 0.6 to reject results affected by strong site effects or 3-D heterogeneity and (3) had null splitting rejected at 95 per cent confidence level or higher. Fig. S2 presents an example of the process for the direct $S$ wave splitting measurements using the RST at station pair LVND (reference)-IVRI (target). Our $S$ wave analysis and its subsequent quality check procedure returned a total of 1624 reliable non-null measurements from 354 teleseismic events for the three arrays (see Table S1).

\section{RESULTS}

The rose diagrams of individual measurements and averaged splitting parameters for each station are shown in Fig. 3 [SK(K)S results] and Fig. 4 (S results). The stereographic plot of splitting measurements at each stations varying with backazimuth and incidence angle are shown in Fig. S3. In order to calculate station-averaged parameters we took the arithmetic mean for the delay times and used the von Mises method (Cochran et al. 2003) to calculate the circular mean of the FPDs. For the direct $S$ waves, at each target station we first averaged the measurements obtained from all the reference stations for a given event and then took the total average over all events.

\section{SK(K)S splitting parameters}

Fig. 3 displays the results of the $\mathrm{SK}(\mathrm{K}) \mathrm{S}$ measurements on the regional map. Statistics for each station are given in Table S2. The total average of delay times for the entire region is $1.14 \pm 0.42 \mathrm{~s}$, and the average values of the three arrays differ from each other by no more than $0.06 \mathrm{~s}$. The FPDs at stations located throughout NW Iran, inside the Talesh and Alborz ranges, and in the Caspian region are dominated by a uniform NE-SW trend with an average azimuth of $37 \pm 8^{\circ}$. This direction closely matches with the APM vector in $\mathrm{NW}$ Iran trending at $\mathrm{N} 39^{\circ} \mathrm{E}$. Stations located outside the aforementioned regions exhibit FPDs that deviate from this regional trend. FPDs observed for the five westernmost stations of Array 1, which are located near the UDMA region indicate a rotation towards NWSE. The southern stations of Array 2 are situated in the transition zone between the Alborz and central Iran, and their fast directions also display NW-SE orientation. In the southern end of Array 3, situated on the northern limits of central Iran, the fast polarizations show more variation with both NE-SW and E-W FPDs. Most of the stations, especially those located in NW Iran, the Talesh, and the Alborz exhibit a unimodal distribution of FPDs largely independent from the initial polarization direction of the SK(K)S phase (rose diagrams in Fig. 3), which implies a single-layer anisotropic structure. Exceptions to this general pattern are observed at several stations in the southern end of Arrays 2 and 3, located on the northern margins of central Iran (e.g. stations SHIV, SABZ, KRUD, $\mathrm{SADQ}$ and $\mathrm{AQCH}$ ), for which the diagrams show two or three lobes. For eight stations in our database, our analysis resulted in only one or two reliable splitting measurements. Despite the low number of measurements, for most of these stations we found average FPDs that are more or less consistent with their neighbouring stations (e.g. IRAN, BEIG, NALB, EMAM and HAMI). This coherency gives a measure of confidence about the reliability of their results. Station CHES in Array 2 has only one splitting measurement and we will not attempt to interpret it. For five stations of Array 3 located in the mountain ranges south of Buyin Zahra, station-averaged FPDs show significant variations. Three of the stations (AQCH, SADQ and NASH), had five or more reliable splitting measurements with approximately E-W oriented FPDs. The other two stations, HEJB and KRUD located in the south of Buyin Zahra, only had 2 and 3 splitting measurements, respectively, and were identified by NESW oriented fast directions. Since it would be unlikely for the anisotropic structure to vary so much over small distances, and given the low number of measurements obtained for stations HEJB and KRUD, we therefore assume that the fast axes in this region are mostly E-W oriented.

Blue bars in Fig. 3 show the initial polarization directions of $\mathrm{SK}(\mathrm{K}) \mathrm{S}$ waves that returned null results. A majority of these polarizations are either nearly parallel or perpendicular to the direction of the fast or slow axis, such that null splitting measurements are expected for these backazimuths. As the number of measurements (both null and non-null) at the stations increases, the match between the null-returning initial polarizations and the FPDs generally improves. Good examples are observed at stations JAMS and SANG with four years of continuous data. At some stations the null measurements are from different initial polarization directions suggesting locally complex anisotropy, or scattering from heterogeneous structures. As most of our stations have a limited back-azimuthal coverage (Fig. 2), a modeling of multilayered anisotropy would be poorly constrained and thus does not seem warranted. Nevertheless, the unimodal pattern of the splitting measurements in most of the stations suggests that a single-layer anisotropy structure is sufficient to explain the splitting observations in NW Iran and the mountain ranges.

\section{Direct $S$ wave splitting parameters}

As mentioned earlier we started the iterative RST process with three initial reference stations selected for each of the arrays. We chose the reference stations among those with the most reliable and well-constrained splitting parameters and good backazimuthal distribution, ensuring a good regional distribution; this was achieved by choosing the station with the largest number of good and fair $\mathrm{SK}(\mathrm{K}) \mathrm{S}$ measurements within each array, also checking whether the single-event splitting estimates show internal consistency. Splitting parameters obtained at each iteration are shown in Fig. S4. At the end of the first iteration, the minimum relative residual energy achieved for the three arrays was $0.021,0.025$ and 0.055 , while the residual energy resulting from zero splitting was $0.79,0.88$ and 1.08 


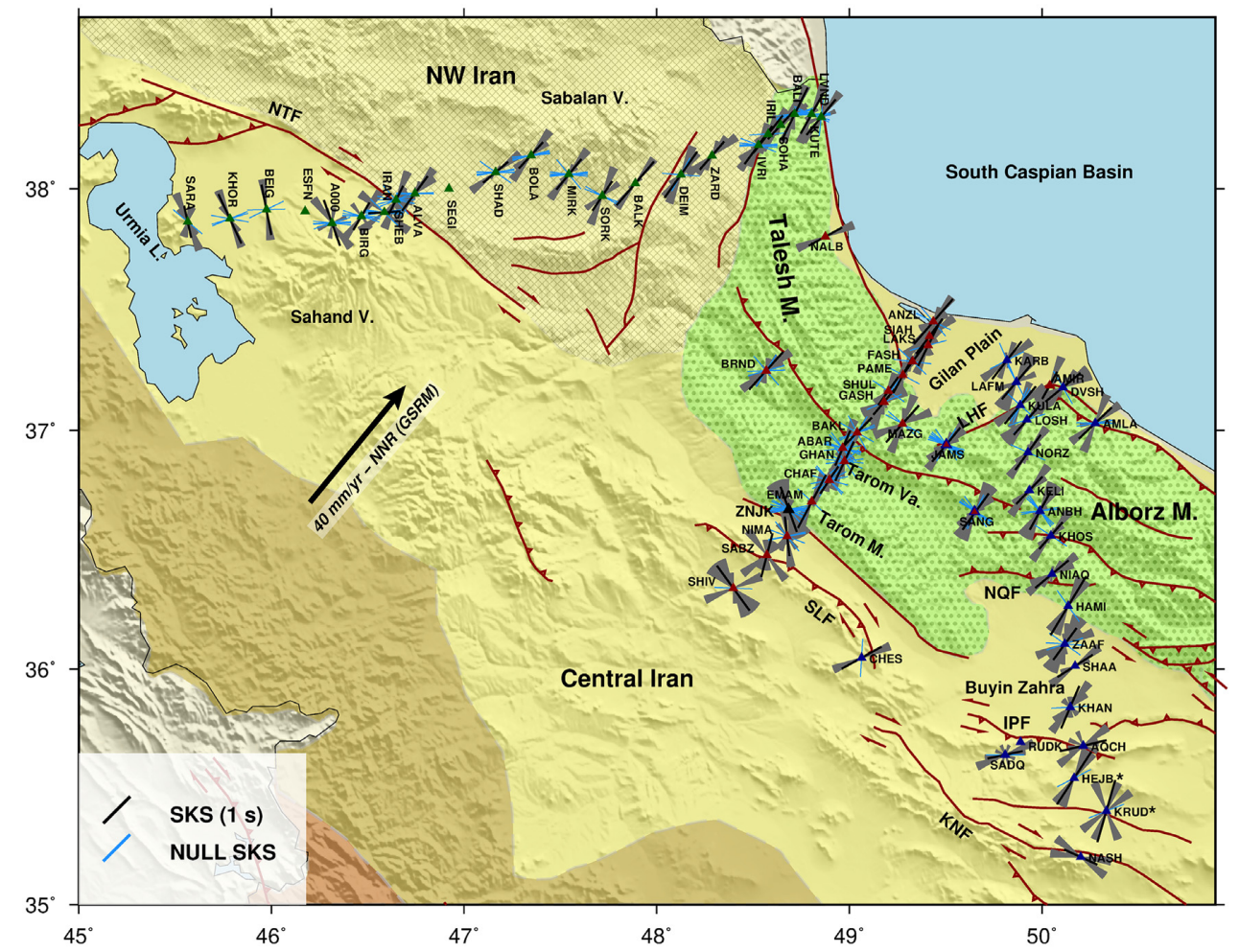

Figure 3. Rose diagrams, station averages and null measurements for the $\mathrm{SK}(\mathrm{K}) \mathrm{S}$ wave superimposed on the tectonic map shown in Fig 1. At each station, the rose diagram histograms of the individual FPD measurements (grey wedges) are shown alongside the station-averaged FPDs (black bar). The length of bars is proportional to the mean splitting delays. Stations with $*$ were deemed unreliable.

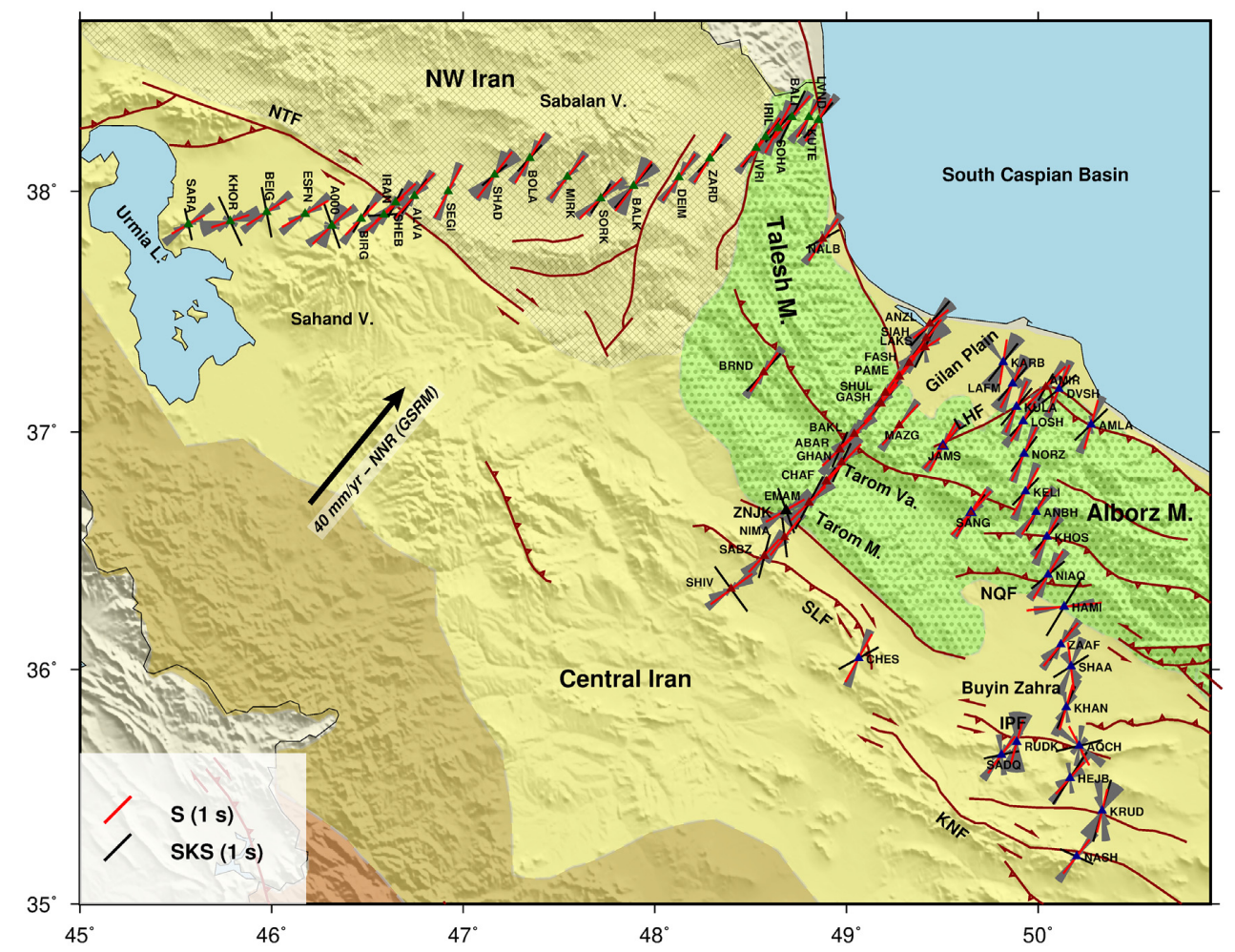

Figure 4. Rose diagrams (histograms of event-averaged $S$ measurements, grey wedges) and station averages for the $S$ wave (red bars) superimposed on the tectonic map. SK(K)S station averages are also shown by black bars. Stations JAMS and SANG operated in both Array 2 and 3 . The two arrays did not operate concurrently. Consequently, we report two station-average FPDs for JAMS and SANG. The two average values differ by less than $10^{\circ}$, though. 
respectively. In each array, most of the stations became a reference station from iteration 2 onwards. The minimum residual energies settled around their minimum value $(0.011,0.012$ and 0.032$)$ after iteration 2 or 3 , but we carried out the process for one or two extra steps. We prevented stations with no SK(K)S result from becoming a reference station. The application of the $\alpha$ parameter was effective in obtaining reliable results in cases where one of the stations was located on the Caspian sediments and the other one in the mountain regions. It allowed us to balance the waveform amplitudes of the two stations and helped to retain those measurements in the database. The RST procedure enabled us to add to the splitting database three stations (ESFN, SEGI, and RUDK), which did not produce a reliable SK(K)S measurement.

Fig. 4 shows the results of the splitting measurements based on direct $S$ waves in comparison with the $\mathrm{SK}(\mathrm{K}) \mathrm{S}$ results. The average delay time $\delta \mathrm{t}$, for the entire data set is $1.36 \pm 0.26 \mathrm{~s}$, which is $0.22 \mathrm{~s}$ more than that of the SK(K)S phase. For Array 1 in NW Iran, the $S$ wave-derived FPDs are consistent with an overall NE-SW orientation, just as the $\mathrm{SK}(\mathrm{K}) \mathrm{S}$ results. We observe a smooth rotation from a more east-west direction near the UDMA in the west to a more northerly direction in the Talesh region in the east. Across Array 2, the dominant directions of FPDs are NE-SW with no significant variation along the profile. In Array 3, the Alborz Mountains north of the North Qazvin Fault (NQF) are characterized by NE-SW oriented FPDs, which appear to be fairly similar to the fast azimuthal pattern detected in the Talesh and Tarom regions. South of the NQF, in central Iran, the FPDs deviate from the regional NE-SW trend and become oriented more in the N-S direction. Station HAMI produced only one $S$ wave splitting measurement, which is inconsistent with the neighbouring stations. We therefore consider the result of this station not reliable. Compared to the rest of the study region where FPDs show considerable uniformity both at the individual stations and between the stations, many of the stations in the southern part of Array 3 exhibit significant variations in individual splitting measurements, as well as changes between stations over short distances.

We can summarize the patterns of FPD variations for both phases as follows: In NW Iran and the Talesh and Alborz ranges, which collectively encompass most of our study area, both SK(K)S and $S$ waves have produced consistent NE-SW oriented FPDs (Figs 3 and 4). The similarity of the splitting parameters for these regions suggests that they constitute a uniform block as far as their anisotropic character is concerned. In the central Iranian domain immediately west of the North Tabriz Fault, as well as south of the Tarom Mountains, the $\mathrm{SK}(\mathrm{K}) \mathrm{S}$ fast axes abruptly change to NW-SE and N-S directions. In contrast, in the same regions the $S$ wave fast axes show much more gentle variations and maintain a general NE-SW direction when the tectonic boundary is crossed; in NW Iran moving further west, they smoothly rotate to a nearly $\mathrm{E}-\mathrm{W}$ direction. In the Buyin Zahra region in the southeast of the study region, we do not observe abrupt changes in the pattern of the $\mathrm{SK}(\mathrm{K}) \mathrm{S}$ fast axes at the Alborz-central Iran boundary across the NQF zone, but further south in the mountains south of Buyin Zahra, they vary on a small scale, with the dominant trend being subparallel to the approximately E-W strike of the mountains and the faults bounding them (IPF and KNF). The $S$ wave fast axes, on the other hand, change to a more-or-less N-S orientation just south of the NQF. Overall, both shear phases appear to distinguish, to varying degrees, between central Iran and the tectonic blocks to the northeast of it with the $\mathrm{SK}(\mathrm{K}) \mathrm{S}$ phase having greater sensitivity than the direct $S$ wave to structural changes.

\section{DISCUSSION}

\section{Comparison between SK(K)S and $S$ wave splitting parameters}

In comparing the splitting measurements of the $\mathrm{SK}(\mathrm{K}) \mathrm{S}$ and direct $S$ waves, an important question is how much of the differences are due to the quantity of the available data and how much can be attributed to the way the two phases sample the anisotropic medium. The scatter plots in Fig. 5 attempt to address this question by displaying the differences in the $\mathrm{SK}(\mathrm{K}) \mathrm{S}$ and $S$-derived average splitting parameters as a function of the number of $\mathrm{SK}(\mathrm{K}) \mathrm{S}$ and $S$ wave measurements. It was observed in several studies (e.g. Eken \& Tilmann 2014; Tiwari et al. 2017) that most of the large differences in FPDs and delay times could be attributed to the low numbers of SK(K)S measurements at those stations. If the two datasets both have reliable measurements and they still produce dissimilar results, then the variance could be attributed to lateral changes in anisotropic structure combined with the path differences between the two phases. According to Fig. 5, out of 66 stations, 15 have an FPD difference larger than $30^{\circ}$, but only 6 of them (KHOR, BEIG, IRAN, NIMA, HAMI and SHAA) have less than 5 SK(K)S splitting measurements. The other nine stations have high numbers of SK(K)S measurements. Therefore, we cannot establish a clear correlation between low number of $\mathrm{SK}(\mathrm{K}) \mathrm{S}$ measurements and large differences in FPDs. We conclude that the large difference between $\mathrm{SK}(\mathrm{K}) \mathrm{S}$ and $S$-derived splitting parameters can have a physical meaning.

To track the propagation paths of the SK(K)S and direct $S$ waves in our region, we have plotted in Fig. 6, the fast axes of the individual measurements of the two waves above the piercing points of their rays at $150 \mathrm{~km}$ depths (black and red bars, respectively) and the incoming rays of the two waves projected onto each of the seismic arrays. This kind of representation is helpful in visualizing the geographical extent of the anisotropic volume sampled by the waves. According to the figure, the subvertically travelling $\mathrm{SK}(\mathrm{K}) \mathrm{S}$ rays sample the asthenosphere and lithosphere inside a narrow region in the near vicinity of the stations, whereas the $S$ rays travel on much-longer non-vertical paths inside the asthenosphere and lithosphere before reaching the stations. Piercing points of $S$ rays at $150 \mathrm{~km}$ depth, can be located at a horizontal distance of $200 \mathrm{~km}$ from the stations (Fig. 6a). The great majority of $S$ wave single measurements exhibit uniformity in FPDs irrespective of the direction of the incoming ray, that is rays with southern and southwestern backazimuths produce the same NE-SW trending fast axes as those approaching from north and northeast. Apart from a minor perturbation among the fast axes for rays arriving at the western stations of Array 1 on paths parallel with the North Tabriz Fault (the region surrounding the Sahand volcano), the $S$ wave fast axes, in contrast to the $\mathrm{SK}(\mathrm{K}) \mathrm{S}$ wave, do not show a notable sensitivity to tectonic boundaries over short length-scales. They instead show a more-or-less uniform anisotropic structure even across the boundaries between major lithospheric blocks. This observation could be explained by the relatively increased effect of the asthenosphere on the direct $S$ wave anisotropy with respect to the lithosphere. The reason for why the $S$ waves should be more sensitive to the asthenosphere is not entirely clear. One explanation could be that in a heterogeneous lithosphere the larger zone of influence of the $S$ wave tends to cancel out the smaller-scale variations, whereas in the asthenosphere the flow field is coherent and the common patterns of anisotropy are actually enhanced through the averaging effect of the $S$ wave. To summarize the interpretation of the results of the two 
(a)

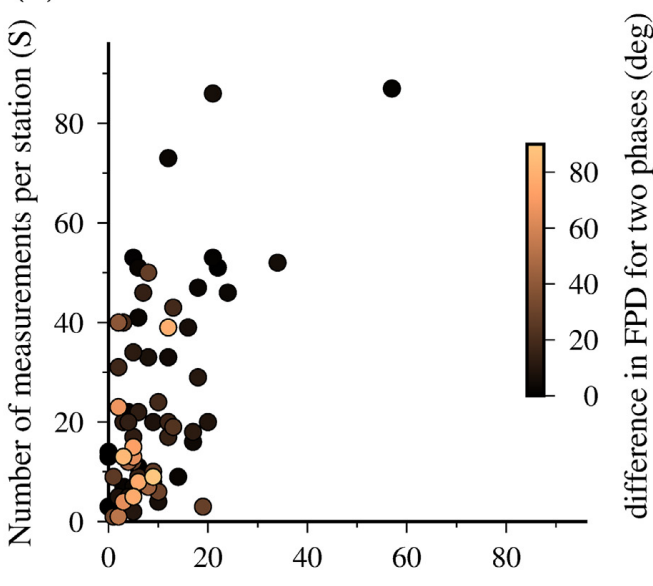

Number of measurements per station (SKS) (b)

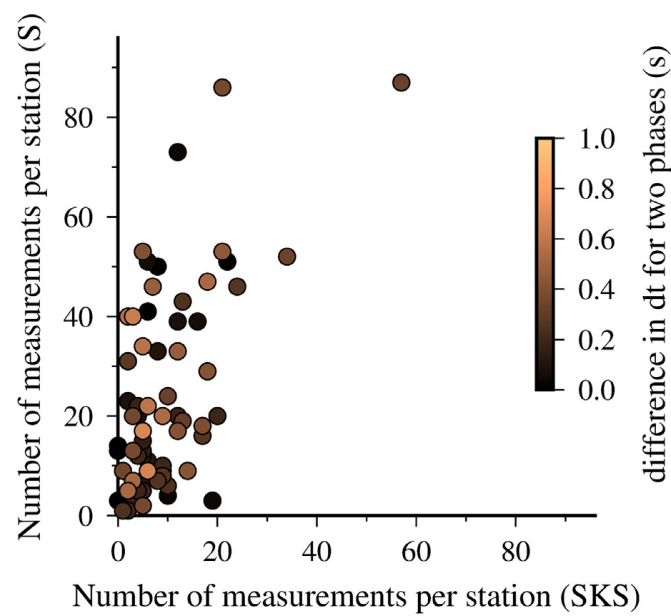

Figure 5. Comparison between the station-averaged SK(K)S and direct $S$ splitting parameters. (a) Scatter plot of the number of individual FPD measurements at stations for the direct $S$ wave versus $\mathrm{SK}(\mathrm{K}) \mathrm{S}$ wave. (b) The same plot for the delay times. The coloring of the data points represents the difference in the splitting parameter measured by the two phases.
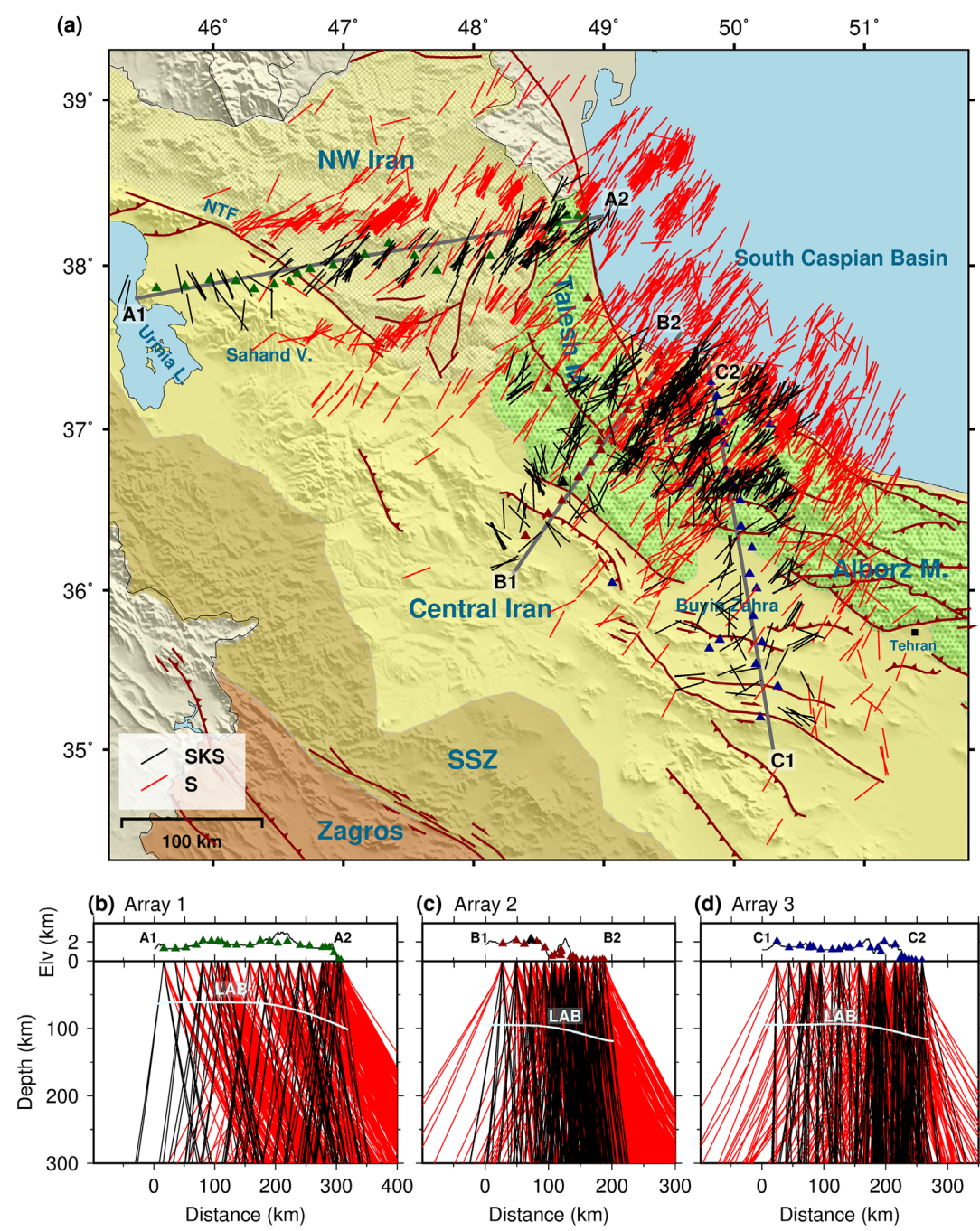

(c) Array 2

(d) Array 3

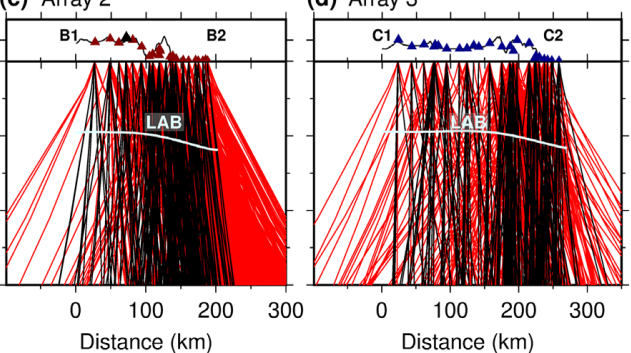

Figure 6. (a) Map of the individual FPDs plotted above the corresponding piercing points at $150 \mathrm{~km}$ for SK(K)S (black bars) and $S$ (red bars). (b) The black and red solid lines reveal the ray path of SK(K)S and $S$, along the Array 1, respectively. (c) and (b) are the same as (b) for Array 2 and 3. 
phases, the direct $S$ wave fast directions seem to map the general direction of the prevailing sublithospheric mantle flow field beneath the northeastern margin of central Iran, as well as under NW Iran and the Alborz. This flow field has a NE direction away from the collisional front of the Zagros in the southwest. The SK(K)S fast directions in most cases also map the same sublithospheric flow field, but they are locally affected by strong anisotropy of the intensely deformed lithosphere on the boundary zone of central Iran and its northern neighbouring blocks.

The only significant variation of $S$ wave fast axes is observed in the southern stations of Array 3 in the Buyin Zahra region. Rays approaching those stations from southeast and east have produced fast directions that roughly trend $\mathrm{N}-\mathrm{S}$, discordant with surface geological trends and also with the local APM vector. These waves travel through a different part of the asthenosphere in central Iran that lies to the southeast of our region of study (the region south of Tehran), and the change in fast directions from west to east of our region can be an indication of possible changes in mantle flow field beneath this part of central Iran. These changes in the flow field can arise from variations in the geometry, thickness, and the dip of the advancing Arabian lithosphere along the collisional front.

Figs 4 and 7 compare the delay times and FPDs for both phases along each of the three arrays. In general the $S$ wave delays are slightly larger than the SK(K)S delay times. The observed differences are mostly larger than the error bounds suggesting that they are physically meaningful. The $\mathrm{SK}(\mathrm{K}) \mathrm{S}$ phases travel nearly vertically, and as a result, traverse a shorter path inside an anisotropic volume than the direct $S$ waves, producing a smaller delay time. A few stations in central Iran (e.g. KHOR, BEIG, ZNJK, SHIV, KRUD, HEJB and AQCH), deviate from this general rule and have an $\mathrm{SK}(\mathrm{K}) \mathrm{S}$ delay time larger than the $S$ wave. Figs 3 and 7 show that the NW Iran stations (Array 1) in the north of the Sahand Volcano (i.e. SHEB, IRAN and BIRG) and those in the south of the Sabalan Volcano (SHAD, BOLA, MIRK and SORK) consistently have smaller SK(K)S delay times than the regional average. Their average delay is $0.89 \mathrm{~s}, 0.24 \mathrm{~s}$ smaller than the average delay of Array 1 . However, the $S$ wave delay times do not show a corresponding variation in their magnitude in the vicinity of the volcanoes. NW Iran is a region of anomalously warm crust and upper mantle and the Sahand and Sabalan have had post-collisional magmatic activities as recently as Pliocene-Quaternary (Chiü et al. 2013). The regional Pg-wave tomography of Maheri-Peyrov et al. (2020) and the $P$-wave tomography of Bavali et al. (2016) revealed low-velocity zones at mid-crustal to subcrustal mantle depths directly beneath the volcanoes, which could be related to their thermal source regions. This structural setting can create a layered anisotropy at a local scale and explain the smaller delay times in the regions of the two volcanoes.

To summarize, the FPDs from the two data sets also show similar patterns. In NW Iran, and Talesh and the Alborz mountains, the SK(K)S and $S$ wave fast axes all trend NE-SW, with a difference of less than $10^{\circ}$ from the average in most of the stations. The fast axes of the $S$ wave vary more gradually than those of the SK(K)S wave. Significant differences in the FPDs of the two waves are observed at the stations located near the boundaries of central Iran or in its interior. The SK(K)S waves, being a phase capable of sampling smaller lateral heterogeneities, have captured this difference. The $S$ waves, on the other hand, are presumably less sensitive to small-scale variations of structure and thus vary more smoothly across contrasting tectonic block boundaries. The $S$-derived FPDs in the central Iran part of Array differ from those in the Alborz part in showing strong variability; they also do not always agree with the $\mathrm{SK}(\mathrm{K}) \mathrm{S}$ fast axes. This indicates that in the interior of central Iran anisotropy is characterized by heterogeneous anisotropic patterns.

\section{Geodynamic interpretation and comparison with previous studies}

In the Alborz, Talesh and NW Iran the FPDs from both phases show no correlation with surface geological features such as the strikes of the mountain ranges and the trend of the major fault zones. Neither do they correlate with the Eurasia-fixed GPS vectors (Fig. 1). Instead, they are in close agreement with the direction of the APM vectors in the no-net-rotation frame (Figs 3 and 4). These observations suggest that the main source of anisotropy in NW Iran and regions surrounding the South Caspian Basin must be in the shallow asthenosphere as it is being sheared near the base of the lithosphere. It seems that the crust and mantle lithosphere do not play a significant role in the observed anisotropy in these regions. This can be a plausible explanation if the lithosphere is thin and the relative motion of the lithosphere and deeper mantle is large enough to generate the large strains needed for the development of a strong anisotropic fabric (e.g. Confal et al. 2018). The high rate of $40 \mathrm{~mm} \mathrm{yr}^{-1}$ for the APM velocity in western Iran (Kreemer et al. 2014-GSRM v2.1 model) makes the development of a thick, strong layer with shearing-induced LPO feasible (Debayle \& Ricard 2013). The resultant large strength of anisotropy in the asthenosphere would be consistent with our relatively large splitting delay time estimates. The general picture that the seismic studies mentioned above convey is that central Iran and the Alborz possess a relatively thin lithosphere and might even have undergone a delamination process (Maggi \& Priestley 2005; Rastgoo et al. 2018), in contrast to the Zagros range, which has a very thick lithospheric root (estimated in excess of $240 \mathrm{~km}$ by some studies). These observations lend credence to the suggestion that anisotropy in a major part of our study area might be controlled by the upper mantle flow field rather than by the deformational fabric of the lithosphere.

Our results are in agreement with the SK(K)S-derived FPDs estimated by Sadeghi-Bagherabadi et al. (2018a) who carried out a study over an expansive region in western Iran near arrays 2 and 3 (Fig. 1). Their FPDs indicate a NE-SW orientation in the western Alborz Mountains; they change to NW-SE just south of the Alborz and become E-W oriented further south in the interior of central Iran. NE-SW fast-axes have also been observed by Sadidkhouy et al. (2008) in the southern flank of central Alborz east of our region, and by Kaviani et al. (2009) farther east in the Kopet Dag Mountains of northeastern Iran. Sadeghi-Bagherabadi et al. (2018a) and Sadidkhouy et al. (2008) attributed their observations in the Alborz to the role of the asthenospheric flow field. Further west in eastern Turkey and in Anatolia, SK(K)S fast directions are dominated by a regional NE-SW trend (Sandvol et al. 2003 and Paul et al. 2014), subparallel with the direction of APM vectors. Various seismic tomography models and converted phases studies (e.g. Gök et al. 2007; Salaün et al. 2012; Kind et al. 2015; Confal et al. 2020) have shown an anomalously low-velocity uppermost mantle and a thin lithospheric structure (i.e. 80-100 km) beneath Anatolia. Spatial distribution of isotropic and anisotropic velocities in seismological observations/models has favored a hypothesis of an asthenospheric source region in Anatolia. Confal et al. (2018) successfully reproduced the lateral variation of present-day anisotropy by modelling the LPO, which develops in response to convective 


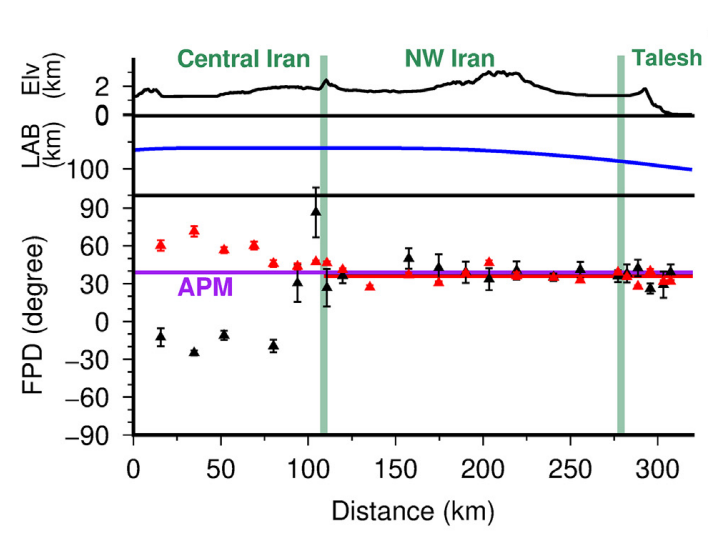

Array 1
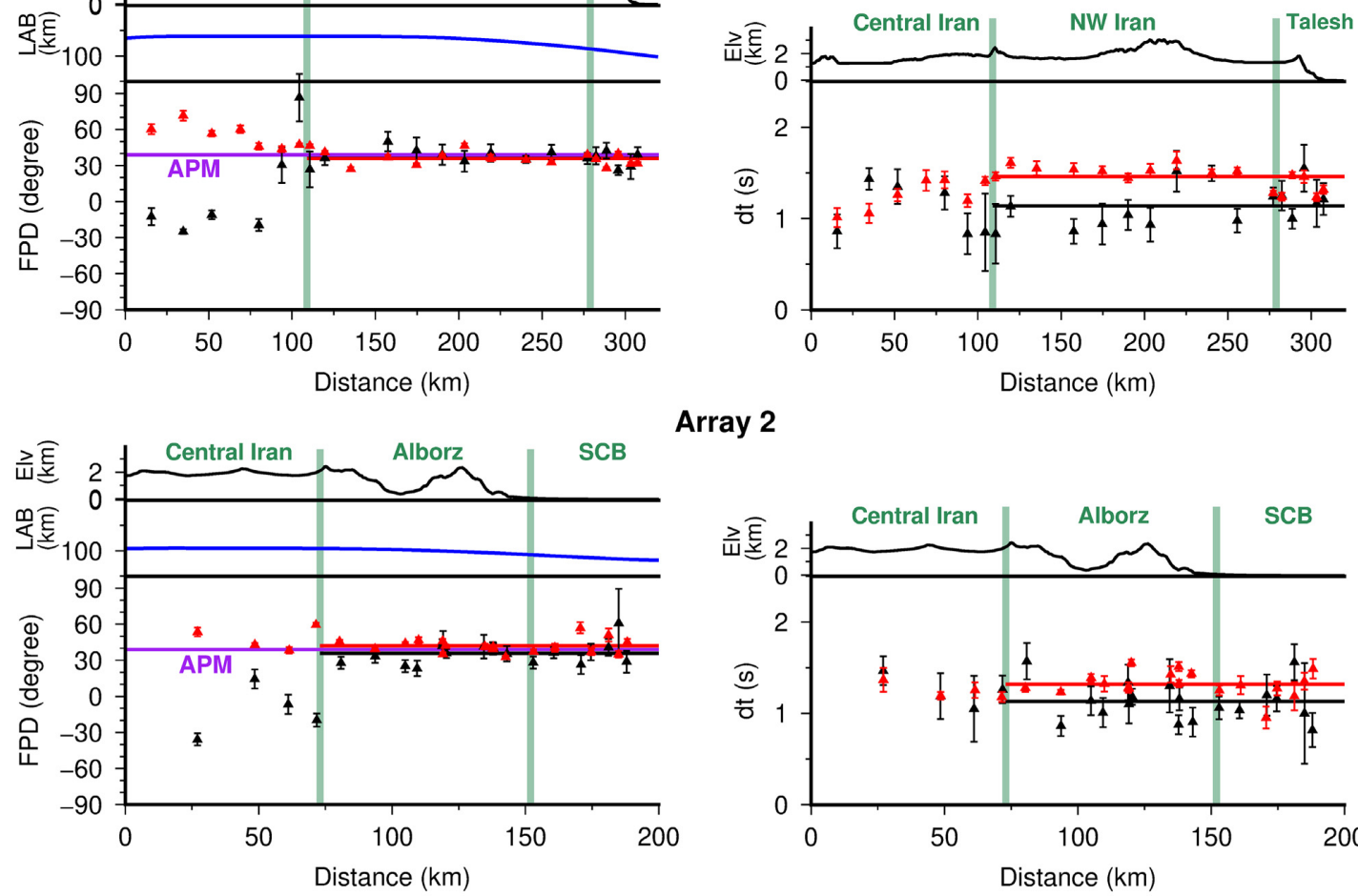

Array 2

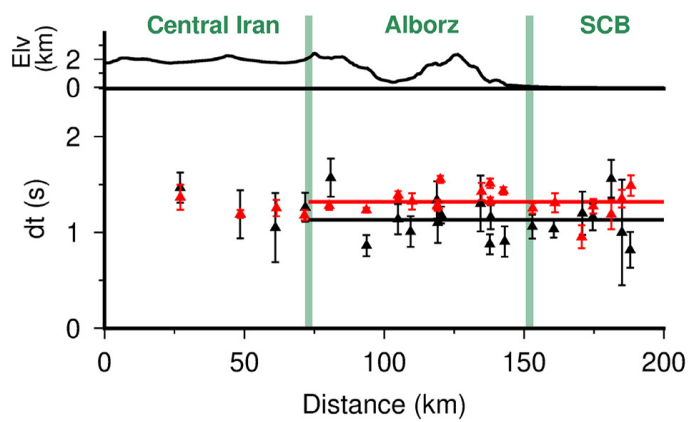

Array 3
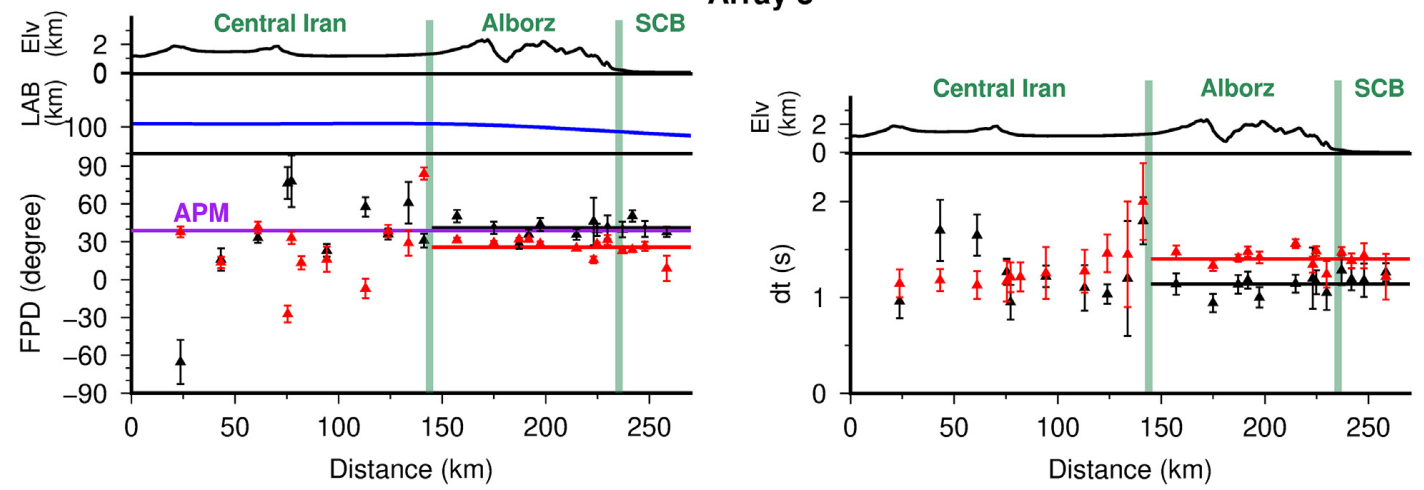

Figure 7. Variations of splitting parameters with their error bars along the three seismic arrays. Black and red symbols represent the SK(K)S and direct $S$ wave measurements at each station, respectively. Solid purple lines represent the trends of APM. Solid black and red are the average splitting parameters in stations located in NW Iran, Talesh, SCB and Alborz for SK(K)S and $S$ derived, respectively. Solid blue lines show the LAB depth beneath each array.

mantle flow within a region covering the eastern Mediterranean and Anatolia. The whole region stretching from Anatolia to northeastern Iran comprises the northern hinterland of the Arabia-Eurasia collision zone. Throughout this vast extent, the lithosphere is thin, and the FPDs thus show NE-SW trends with a remarkable degree of uniformity. Our observations combined with previous studies suggest that far north of the collision zone the anisotropic structure in the upper mantle is controlled by a coherent asthenospheric flow field dominated by basal shear, resulting in broadly APM parallel fast directions.

In central Iran, most of the SK(K)S-derived fast directions trend NW-SE, which is sub-parallel to the major geological structures, notably the strike-slip systems of the NTF, SF and KNF as well as the regional trend of the UDMA. The fast axes rapidly rotate from range-perpendicular in NW Iran and the Alborz to range-parallel in central Iran. The western margin of central Iran is characterized by a strip of active shear zones that run parallel to the SSZ stretching from northwestern Iran to near the southeastern termination of the Zagros Mountains. The North Tabriz and Soltanieh fault zones and the set of faults south of the Buyin Zahra in our region of study (KNF and IPF) are part of these shear zones. Many of the FPDs near these fault zones strike subparallel to them. Kaviani et al. (2009) in their analysis of anisotropy over the entire Iran region (Fig. 1) observed that the $\mathrm{SK}(\mathrm{K}) \mathrm{S}$ fast axes are mostly subparallel with the dominant direction of shear inside the shear zones of central Iran. They saw good correlations between patterns of anisotropy and lithospheric deformation, and hence argued for a lithospheric origin of anisotropy. Fig. 1 shows the direction of maximum shear strain rate calculated from GPS vectors by Raeesi et al. (2017). The direction of shear in central Iran is consistently 
NW-SE and subparallel with the active strike-slip fault zones in the study area. It also matches with the direction SK(K)S-derived fast axes. The agreement between the pattern of geodetic and geological finite strain in the crust and the finite strain of the mantle as inferred from the $\mathrm{SK}(\mathrm{K}) \mathrm{S}$ splitting parameters implies that the dominant source of anisotropy resides inside the lithosphere. This suggestion is reaffirmed by the fact that the Zagros collision zone is a region of intense deformation and the central Iran lithosphere is accommodating a significant part of the total strain.

Sadeghi-Bagherabadi et al. (2018a) mapped the variations of $\mathrm{SK}(\mathrm{K}) \mathrm{S}$ fast axes in central Iran from the Zagros to the edge of SCB (Fig. 1) and showed a complicated pattern of fast axes where they repeatedly change from range-perpendicular to range-subparallel. Based on this observed variability, Sadeghi-Bagherabadi et al. (2018b) put forward the alternative interpretation that the observed anisotropy over central Iran mostly reflects the pattern of an asthenospheric flow field beneath a thin lithosphere affected by the keel of a thick Zagros lithosphere and an edge-driven small-scale convective flow in the region of strong lithospheric thickness gradient. Specifically, they partially attributed the NW-SE fast orientations along the NW margin of central Iran (coincident with our study area) to toroidal convective flow, which establishes a horizontal component normal to the lithospheric gradient (Kaislaniemi \& van Hunen 2014). At the same time they acknowledged that those trends could also have their origin in the lithosphere. The small-scale mantle flow fields as described by Sadeghi-Bagherabadi et al. (2018b) imply that asthenospheric anisotropy might be strongly localized and not give rise to a coherent pattern, potentially allowing the lithospheric fabric arising from the shear zones to dominate over the anisotropy of the layer underneath it.

Several studies have investigated the azimuthal anisotropy of the Pn velocity over the Iran region (Al-Lazki et al. 2004; Lü et al. 2012; Al-Lazki et al. 2014). All of them show a patchy pattern of variations of Pn anisotropy but in many regions a relation with surface geological structures can be identified. In NW Iran, the Pn fast direction has a dominant NE-SW orientation, very similar to the $\mathrm{SK}(\mathrm{K}) \mathrm{S}$ and $S$ wave fast axes we have obtained on Array 1. In the western Alborz and the Tarom regions, Pn anisotropy is lowintensity to negligible and its fast direction is overall $\mathrm{E}-\mathrm{W}$, which does not match well with the NE-SW fast axes obtained from the shear wave splittings. In the central Iran part of our study area, Pn anisotropy shows more affinity with surface structures; south of the Tarom Mountains the Pn fast directions trend NW-SE and in Buyin Zahra and the mountains south of it they rotate to a more-or-less $\mathrm{E}-\mathrm{W}$ direction. In these regions there is a broad agreement between Pn and SK(K)S fast direction. The $S$ wave fast axes, however, match less with the pattern of Pn directions. The Pn wave is sensitive to the shallowest mantle and its anisotropy and therefore probes the current or fossil deformation of the lithospheric mantle, unless the mantle lithosphere is absent or extremely thin. In NW Iran, the abovementioned studies have revealed low isotropic and anisotropic Pn velocity anomalies. This region also has a very thin lithosphere, as thin as $70 \mathrm{~km}$ (see Fig. 1), and a crustal thickness of about $50 \mathrm{~km}$. These lines of evidence suggest that the mantle lid of NW Iran is very thin, and thus, Pn might be influenced by the deformation of the asthenosphere, which would explain the observed match between the fast direction of Pn and that of the mantle shear phases in NW Iran. In the western Alborz, the lithosphere is relatively thicker than in NW Iran, but given that Pn anisotropy is not particularly strong in this region, lithospheric anisotropy does not seem to make a large contribution to the splitting measurements from the SK(K)S and $S$ phases. The unimodal fast-axis distribution at most of the stations suggests a lack of strong anisotropic layering in the region. In the case of NW Iran and Alborz, the subcrustal mantle may not be able to form a strong layer to influence the observed anisotropy. In central Iran, sub-crustal anisotropy as inferred from Pn seems to be stronger and its fast direction correlates better with the SK(K)S fast axes. We have already argued that the $\mathrm{SK}(\mathrm{K}) \mathrm{S}$ splitting results in central Iran have a lithospheric origin. The match between the Pn and $\mathrm{SK}(\mathrm{K}) \mathrm{S}$ fast directions, then implies that the entire thickness of the mantle lithosphere undergoes a coherent deformation.

\section{CONCLUSIONS}

Our splitting measurements cover a part of the plateau region that has formed on the back side of the Arabia-Eurasia collision zone, and they reveal the details of the mantle flow field and the deformation of the upper plate of the collision. The majority of the delay times for both direct $S$ and $\mathrm{SK}(\mathrm{K}) \mathrm{S}$ phases are in the range of 1$1.5 \mathrm{~s}$. These are within the high range of values for active continental regions (Silver 1996) and indicate that the mantle is undergoing intense deformation. The $\mathrm{S}$ and $\mathrm{SK}(\mathrm{K}) \mathrm{S}$ fast orientations are largely in agreement with each other and map a NE-SW directed mantle flow field, approximately parallel to the APM direction. The smooth variation of splitting parameters over most of the study region is an indication that they are unlikely to originate from shallow depths. Furthermore, they do not correlate with surface geology, implying that the crust and mantle lithosphere probably do not make strong anisotropic layers to significantly affect the observations. Also, the thickness of the lithosphere in central Iran and the Alborz is less than the average for continental lithosphere. As the lithosphere of Arabia and Eurasia move in the NE direction, the shearing of the asthenosphere at the base of the lithosphere creates olivine LPO fabric in the asthenospheric mantle, which can explain our observations. The SK(K)S waves sample comparatively narrower regions around the stations than the $S$ waves do, and so they are able to detect potential changes in the anisotropic characters of neighbouring blocks, especially if those changes happen inside the lithosphere. On this basis, the $\mathrm{SK}(\mathrm{K}) \mathrm{S}$ fast directions have captured the strong anisotropy that has developed inside the lithospheric shear zones on the margins of central Iran where they locally obscure the effect of the asthenospheric flow field beneath, whereas the $S$ waves remain sensitive to the larger scale asthenospheric pattern. This can explain the systematic differences between the $\mathrm{SK}(\mathrm{K}) \mathrm{S}$ and $S$ wave fast axes in the boundary region of central Iran with NW Iran and the Alborz. We should caution that this explanation is far from definite and needs further measurements and testing in the future.

\section{DATA AND SOFTWARE}

The shear waveforms used for splitting measurements, along with station response information and the measurements in machinereadable form are available at https://doi.org/10.5880/GFZ.2.4.2021 .004. SplitLab and RST codes are publicly available via http://splitt ing.gm.univ-montp2.fr and https://github.com/ftilmann/multisplit.

\section{ACKNOWLEDGEMENTS}

This research was supported by several IASBS internal grants, and the following NERC grants to Cambridge: NERC (Grant Ref: NE/J019895/1), IOF award NE/M017559/1, and RG73719-IAA award NE/L012936/1. SA was supported by a scholarship from the 
Ministry of Science, Research and Technology of Iran to visit Potsdam for 3 months and the Deutsche GeoForschungsZentrum (GFZ) for providing support for another visit. TE is grateful to the Alexander von Humboldt Foundation Research Fellowship Award and the Humboldt-Stiftung Follow-Up Programme for financial support and computing facilities.

\section{REFERENCES}

Agard, P., Omrani, J., Jolivet, L., Whitechurch, H., Vrielynck, B., Spakman, W., Monié, P., Meyer, B. \& Wortel, R., 2011. Zagros orogeny: a subduction-dominated process, Geol. Mag., 148(5-6), 692-725.

Al-Lazki, A.I., Sandvol, E., Seber, D., Barazangi, M., Turkelli, N. \& Mohamad, R., 2004. Pn tomographic imaging of mantle lid velocity and anisotropy at the junction of the Arabian, Eurasian and African plates, Geophys. J. Int., 158(3), 1024-1040.

Al-Lazki, A.I., Al-Damegh, K.S., El-Hadidy, S.Y., Ghods, A. \& Tatar, M., 2014. Pn-velocity structure beneath Arabia-Eurasia Zagros collision and Makran subduction zones, Geol. Soc. Lond., Spec. Publ., 392(1), 45-60.

Allen, M.B., Kheirkhah, M., Emami, M.H. \& Jones, S.J., 2011. Right-lateral shear across Iran and kinematic change in the Arabia-Eurasia collision zone, Geophys. J. Int., 184(2), 555-574.

Amini, S., Shomali, Z.H., Koyi, H. \& Roberts, R.G., 2012. Tomographic upper-mantle velocity structure beneath the Iranian Plateau, Tectonophysics, 554, 42-49.

Bavali, K., Motaghi, K., Sobouti, F., Ghods, A., Abbasi, M., Priestley, K., Mortezanejad, G. \& Rezaeian, M., 2016. Lithospheric structure beneath NW Iran using regional and teleseismic travel-time tomography, Phys. Earth planet. Inter., 253, 97-107.

Bowman, J.R. \& Ando, M., 1987. Shear-wave splitting in the upper-mantle wedge above the Tonga subduction zone, Geophys. J. Int., 88(1), 25-41.

Chiü, H.Y., Chung, S.L., Zarrinkoub, M.H., Mohammadi, S.S., Khatib, M.M. \& Iizuka, Y., 2013. Zircon U-Pb age constraints from Iran on the magmatic evolution related to Neotethyan subduction and Zagros orogeny, Lithos, 162, 70-87.

Cochran, E.S., Vidale, J.E. \& Li, Y.G., 2003. Near-fault anisotropy following the Hector Mine earthquake, J. geophys. Res., 108(B9), doi:10.1029/2002JB002352.

Confal, J.M., Eken, T., Tilmann, F., Yolsal-Çevikbilen, S., Çubuk-Sabuncu, Y., Saygin, E. \& Taymaz, T., 2016. Investigation of mantle kinematics beneath the Hellenic-subduction zone with teleseismic direct shear waves, Phys. Earth planet. Inter., 261, 141-151.

Confal, J.M., Faccenda, M., Eken, T. \& Taymaz, T., 2018. Numerical simulation of 3-D mantle flow evolution in subduction zone environments in relation to seismic anisotropy beneath the Eastern Mediterranean region, Earth planet. Sci. Lett., 497, 50-61.

Confal, J.M., Bezada, M.J., Eken, T., Faccenda, M., Saygin, E. \& Taymaz, T., 2020. Influence of upper mantle anisotropy on isotropic P-wave tomography images obtained in the eastern Mediterranean region, J. geophys. Res., 125(8), doi:10.1029/2019JB018559.

Debayle, E. \& Ricard, Y., 2013. Seismic observations of large-scale deformation at the bottom of fast-moving plates, Earth planet. Sci. Lett., 376, $165-177$.

Eken, T. \& Tilmann, F., 2014. The use of direct shear waves in quantifying seismic anisotropy: exploiting regional arrays, Bull. seism. Soc. Am., 104(6), 2644-2661.

Ghods, A., Shabanian, E., Bergman, E., Faridi, M., Donner, S., Mortezanejad, G. \& Aziz-Zanjani, A., 2015. The Varzaghan-Ahar, Iran, earthquake doublet ( $\mathrm{M} \mathrm{w} \mathrm{6.4,} \mathrm{6.2):} \mathrm{implications} \mathrm{for} \mathrm{the} \mathrm{geodynamics} \mathrm{of} \mathrm{northwest}$ Iran, Geophys. J. Int., 203(1), 522-540.

Gök, R., Pasyanos, M.E. \& Zor, E., 2007. Lithospheric structure of the continent-continent collision zone: eastern Turkey, Geophys. J. Int., 169(3), 1079-1088.

Hessami, K., Jamali, F. \& Tabasi, H., 2003, Major active faults of Iran. $1: 2,500,000$, International Institute of Earthquake Engineering and Seismology, Tehran, Iran.
Kaislaniemi, L. \& van Hunen, J., 2014. Dynamics of lithospheric thinning and mantle melting by edge-driven convection: application to Moroccan Atlas Mountains, Geochem., Geophys., Geosyst., 15(8), 3175-3189.

Karato, S.I., Wang, Z., Liu, B. \& Fujino, K., 1995. Plastic deformation of garnets: systematics and implications for the rheology of the mantle transition zone, Earth planet. Sci. Lett., 130(1-4), 13-30.

Kaviani, A., Paul, A., Bourova, E., Hatzfeld, D., Pedersen, H. \& Mokhtari, M., 2007. A strong seismic velocity contrast in the shallow mantle across the Zagros collision zone (Iran), Geophys. J. Int., 171(1), 399-410.

Kaviani, A., Hatzfeld, D., Paul, A., Tatar, M. \& Priestley, K., 2009. Shearwave splitting, lithospheric anisotropy, and mantle deformation beneath the Arabia-Eurasia collision zone in Iran, Earth planet. Sci. Lett., 286(34), 371-378.

Khorrami, F., Vernant, P., Masson, F., Nilfouroushan, F., Mousavi, Z., Nankali, H., Saadat, S.A., Walpersdorf, A., Hosseini, S., Tavakoli, P. \& Aghamohammadi, A., 2019. An up-to-date crustal deformation map of Iran using integrated campaign-mode and permanent GPS velocities, Geophys. J. Int., 217(2), 832-843.

Kind, R., Eken, T., Tilmann, F., Sodoudi, F., Taymaz, T., Bulut, F., Xuan, X., Can, B. \& Schneider, F., 2015. Thickness of the lithosphere beneath Turkey and surroundings from S-receiver functions, Solid Earth, 6, 971984.

Kreemer, C., Blewitt, G. \& Klein, E.C., 2014. A geodetic plate motion and Global Strain Rate Model, Geochem., Geophys., Geosyst., 15(10), 3849-3889.

Long, M. D. \& van der Hilst, R. D.(2005). Upper mantle anisotropy beneath Japan from shear wave splitting, Phys. Earth planet. Inter., 151, 206-222, doi:10.1016/j.pepi.2005.03.003.

Lynner, C., Long, M.D., Thissen, C.J., Paczkowski, K. \& Montési, L.G., 2017. Evaluating geodynamic models for sub-slab anisotropy: effects of olivine fabric type, Geosphere, 13(2), 247-259.

Lü, Y., Liu, B., Pei, S., Sun, Y., Toksöz, M.N. \& Zeng, X., 2012. Pn tomographic velocity and anisotropy beneath the Iran region, Bull. seism. Soc. Am., 102(1), 426-435.

Maggi, A. \& Priestley, K., 2005. Surface waveform tomography of the Turkish-Iranian plateau, Geophys. J. Int., 160(3), 1068-1080.

Maheri-Peyrov, M., Ghods, A., Donner, S., Akbarzadeh-Aghdam, M., Sobouti, F., Motaghi, K., Hassanzadeh, M., Mortezanejad, G., Talebian, M. \& Chen, L., 2020. Upper crustal structure of NW Iran revealed by regional 3-D Pg velocity tomography, Geophys. J. Int., 222(2), 1093-1108.

Mahmoodabadi, M., Yaminifard, F., Tatar, M., Kaviani, A. \& Motaghi, K., 2019. Upper-mantle velocity structure beneath the Zagros collision zone, Central Iran and Alborz from nonlinear teleseismic tomography, Geophys. J. Int., 218(1), 414-428.

Mahmoodabadi, M., Yaminifard, F., Tatar, M. \& Kaviani, A., 2020. Shear wave velocity structure of the upper-mantle beneath the northern Zagros collision zone revealed by nonlinear teleseismic tomography and Bayesian Monte-Carlo joint inversion of surface wave dispersion and teleseismic P-wave coda, Phys. Earth planet. Inter, 300, 106444, doi:10.1016/j.pepi.2020.106444 PEPI.

Mangino, S. \& Priestley, K., 1998. The crustal structure of the southern Caspian region, Geophys. J. Int., 133(3), 630-648.

Mohammadi, N., Sodoudi, F., Mohammadi, E. \& Sadidkhouy, A., 2013. New constraints on lithospheric thickness of the Iranian plateau using converted waves, J. Seismol., 17(3), 883-895.

Mortezanejad, G., Rahimi, H., Romanelli, F. \& Panza, G.F., 2019. Lateral variation of crust and upper mantle structures in NW Iran derived from surface wave analysis, J. Seismol., 23(1), 77-108.

Motaghi, K., Tatar, M., Priestley, K., Romanelli, F., Doglioni, C. \& Panza, G.F., 2015. The deep structure of the Iranian Plateau, Gondwana Res., 28(1), 407-418.

Motaghi, K., Shabanian, E. \& Kalvandi, F., 2017. Underplating along the northern portion of the Zagros suture zone, Iran, Geophys. J. Int., 210(1), 375-389.

Motaghi, K., Ghods, A., Sobouti, F., Shabanian, E., Mahmoudabadi, M. \& Priestley, K., 2018. Lithospheric seismic structure of the West AlborzTalesh ranges, Iran, Geophys. J. Int., 215(3), 1766-1780. 
Mouthereau, F., Lacombe, O. \& Vergés, J., 2012. Building the Zagros collisional orogen: timing, strain distribution and the dynamics of Arabia/Eurasia plate convergence, Tectonophysics, 532, 27-60.

Nissen, E., Tatar, M., Jackson, J.A. \& Allen, M.B., 2011. New views on earthquake faulting in the Zagros fold-and-thrust belt of Iran, Geophys. J. Int., 186(3), 928-944.

Omrani, J., Agard, P., Whitechurch, H., Benoit, M., Prouteau, G. \& Jolivet, L., 2008. Arc-magmatism and subduction history beneath the Zagros Mountains, Iran: a new report of adakites and geodynamic consequences, Lithos, 106(3-4), 380-398.

Paul, A., Kaviani, A., Hatzfeld, D., Vergne, J. \& Mokhtari, M., 2006. Seismological evidence for crustal-scale thrusting in the Zagros mountain belt (Iran), Geophys. J. Int., 166(1), 227-237.

Paul, A., Hatzfeld, D., Kaviani, A., Tatar, M. \& Péquegnat, C., 2010. Seismic imaging of the lithospheric structure of the Zagros mountain belt (Iran), Geol. Soc. Lond., Spec. Publ., 330(1), 5-18.

Paul, A., Karabulut, H., Mutlu, A.K. \& Salaün, G., 2014. A comprehensive and densely sampled map of shear-wave azimuthal anisotropy in the Aegean-Anatolia region, Earth planet. Sci. Lett., 389, 14-22.

Pilia, S., Jackson, J.A., Hawkins, R., Kaviani, A. \& Ali, M.Y., 2020. The southern Zagros collisional orogen: new insights from transdimensional trees inversion of seismic noise, Geophys. Res. Lett., 47(4), e2019GL086258. doi:10.1029/2019GL086258.

Priestley, K., McKenzie, D., Barron, J., Tatar, M. \& Debayle, E., 2012. The Zagros core: deformation of the continental lithospheric mantle, Geochem., Geophys., Geosyst., 13(11), doi:10.1029/2012GC004435.

Raeesi, M., Zarifi, Z., Nilfouroushan, F., Boroujeni, S.A. \& Tiampo, K., 2017. Quantitative analysis of seismicity in Iran, Pure appl. Geophys., 174(3), 793-833.

Rahmani, M., Motaghi, K., Ghods, A., Sobouti, F., Talebian, M., Ai, Y. \& Chen, L., 2019. Deep velocity image of the north Zagros collision zone (Iran) from regional and teleseismic tomography, Geophys. J. Int., 219(3), 1729-1740.

Rastgoo, M., Rahimi, H., Motaghi, K., Shabanian, E., Romanelli, F. \& Panza, G.F., 2018. Deep structure of the Alborz Mountains by joint inversion of $P$ receiver functions and dispersion curves, Phys. Earth planet. Inter, 277, $70-80$.

Sadeghi-Bagherabadi, A., Sobouti, F., Ghods, A., Motaghi, K., Talebian, M., Chen, L., Jiang, M., Ai, Y. \& He, Y., 2018a. Upper mantle anisotropy and deformation beneath the major thrust-and-fold belts of Zagros and Alborz and the Iranian Plateau, Geophys. J. Int., 214(3), 1913-1918.

Sadeghi-Bagherabadi, A., Margheriti, L., Aoudia, A. \& Sobouti, F., 2018 b. Seismic anisotropy and its geodynamic implications in Iran, the easternmost part of the Tethyan Belt, Tectonics, 37(12), 4377-4395.

Sadidkhouy, A., Javan-Doloei, G. \& Siahkoohi, H.R., 2008. Seismic anisotropy in the crust and upper mantle of the Central Alborz Region, Iran, Tectonophysics, 456(3-4), 194-205.

Salaün, G., Pedersen, H.A., Paul, A., Farra, V., Karabulut, H., Hatzfeld, D., Papazachos, C., Childs, D.M., Pequegnat, C. \& SIMNAAD, Team., 2012. High-resolution surface wave tomography beneath the Aegean-Anatolia region: constraints on upper-mantle structure, Geophys. J. Int., 190(1), $406-420$.

Sandvol, E., Turkelli, N., Zor, E., Gok, R., Bekler, T., Gurbuz, C., Seber, D. \& Barazangi, M., 2003. Shear wave splitting in a young continent-continent collision: an example from Eastern Turkey, Geophys. Res. Lett., 30(24), doi:10.1029/2003GL017390.

Savage, M.K., Silver, P.G. \& Meyer, R.P., 1990. Observations of teleseismic shear-wave splitting in the Basin and Range from portable and permanent stations, Geophys. Res. Lett., 17(1), 21-24.

Savage, M.K., 1999. Seismic anisotropy and mantle deformation: what have we learned from shear wave splitting?, Rev. Geophys., 37(1), 65-106.

Silver, P.G. \& Chan, W.W., 1991. Shear wave splitting and subcontinental mantle deformation, J. geophys. Res., 96(B10), 16 429-16 454.

Silver, P.G., 1996. Seismic anisotropy beneath the continents: probing the depths of geology, Ann. Rev. Earth planet. Sci., 24(1), 385-432.

Singh, A., Eken, T., Mohanty, D.D., Saikia, D., Singh, C. \& Kumar, M.R., 2016. Significant seismic anisotropy beneath southern Tibet inferred from splitting of direct S-waves, Phys. Earth planet. Inter, 250, 1-11, doi:0.1016/j.pepi.2015.11.001.

Taghizadeh-Farahmand, F., Sodoudi, F., Afsari, N. \& Ghassemi, M.R., 2010. Lithospheric structure of NW Iran from $\mathrm{P}$ and $\mathrm{S}$ receiver functions, $J$. Seismol., 14(4), 823-836.

Tiwari, A.K., Singh, A., Eken, T. \& Singh, C., 2017. Seismic anisotropy inferred from direct S-wave-derived splitting measurements and its geodynamic implications beneath southeastern Tibetan Plateau, Solid Earth, 8(2), 435, doi:10.5194/se-8-435-2017.

Tunini, L., Jiménez-Munt, I., Fernandez, M., Vergés, J. \& Villasenor, A., 2015. Lithospheric mantle heterogeneities beneath the Zagros Mountains and the Iranian Plateau: a petrological-geophysical study, Geophys. J. Int., 200(1), 596-614.

Van der Meer, D.G., Van Hinsbergen, D.J. \& Spakman, W., 2018. Atlas of the underworld: slab remnants in the mantle, their sinking history, and a new outlook on lower mantle viscosity, Tectonophysics, 723, 309-448.

Vecsey, L., Plomerová, J. \& Babuška, V., 2008. Shear-wave splitting measurements - problems and solutions, Tectonophysics, 462(1-4), 178196.

Wookey, J., Kendall, J.M. \& Barruol, G., 2002. Mid-mantle deformation inferred from seismic anisotropy, Nature, 415(6873), 777-780.

Wu"stefeld, A. \& Bokelmann, G., 2007. Null detection in shear-wave splitting measurements, Bull. seism. Soc. Am., 97(4), 1204-1211.

Wüstefeld, A., Bokelmann, G., Zaroli, C. \& Barruol, G., 2008. SplitLab: a shear-wave splitting environment in Matlab, Comput. Geosci., 34(5), $515-528$.

\section{SUPPORTING INFORMATION}

Supplementary data are available at $G J I$ online.

Figure S1. Diagnostic plot of a single measurement. Centre panels displays result for the rotation-correlation (RC) technique: (a) seismogram components in fast (solid) and slow (dashed) directions for RC-anisotropy system after RC-delay correction (normalized); (b) radial $(\mathrm{Q}$, solid) and transverse ( $\mathrm{T}$, dashed) components after $\mathrm{RC}-$ correction (not normalized); (c) particle motion before (dashed) and after (solid) RC correction and (d) map of correlation coefficients. Lower panels display results for the minimum energy (SC) technique: (e) seismograms shown after splitting correction shown on SC fast and slow components (normalized); (f) same on radial and transverse components (not normalized); (g) SC particle motion before and after correction and (h) map of minimum energy values on transverse component. In the upper left-hand panel an extended section of $Q$ (solid) and $T$ (dashed) components before anisotropy correction is displayed. In the upper right-hand panel a stereo plot of the result is presented. Header gives specifications of event as well as splitting parameters resulting from three techniques (Eigenvalue and Rotation Correlation result is not considered in this paper).

Figure S2. Examples of the direct $S$ wave splitting measurements based on the RST at station pair LVND (reference station)-IVRI (target station). (a) Misfit surface with splitting parameter $32^{\circ} \pm 5^{\circ}$ and $1.25 \pm 0.25$ s. (b) Signal at reference station (LVND) with receiver-side correction. (c) Signal at target station (IVRI). (d) Fast and slow component after rotating signal at target station (IVRI) using FPD of $32^{\circ}$. (e) Fast and slow component corrected for $\delta t$ of $1.25 \mathrm{~s}$. (f) Corrected radial and transverse components at target station (IVRI) using optimum FPD and $\delta \mathrm{t}$ and isotropic delay of $1.3 \mathrm{~s} .(\mathrm{g})$ Residual trace.

Figure S3. Stereographic plot of splitting measurements at each stations varying with backazimuth (angle from the north) and incidence angle (distance from origin). Red and black bars represent the $S$ and SK(K)S measurements, respectively. Blue circles are showing null SK(K)S measurements. Please note that for $S$ waves, the initial polarization is not determined by the backazimuth, so double 
layer splitting would not lead to a systematic azimuthal variation as expected for SK(K)S.

Figure S4. Splitting parameters obtained from the RST method at the end of each iteration of the bootstrap process. Initial knowledge of SK(K)S-based anisotropy beneath each reference station is shown by the black bar.

Table S1. Information pertaining to the number of splitting measurements for each of the three arrays used in this study.
Table S2. Statistics on the splitting measurements for individual stations of the three arrays. Stations whose average splitting parameters were deemed unreliable are marked by ${ }^{*}$. The reference stations for the RST method of measuring direct $S$ results are marked by $\%$.

Please note: Oxford University Press is not responsible for the content or functionality of any supporting materials supplied by the authors. Any queries (other than missing material) should be directed to the corresponding author for the paper. 